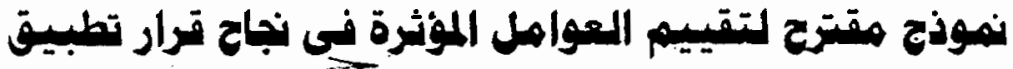

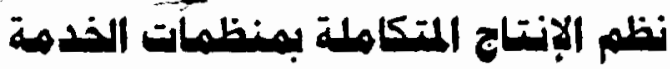

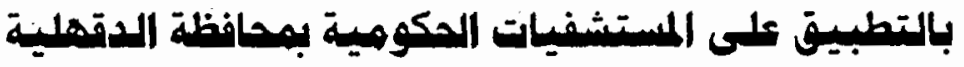

الدكتور / أحمد محمد السبيد غنيم

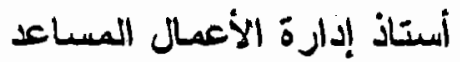

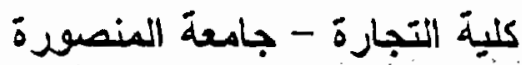

تقديم: ت ت

يعتبر اتجأه المنظمات المعاصرة ندو استخدام نظم الإتتاج المستحدثة من أهم التحديات

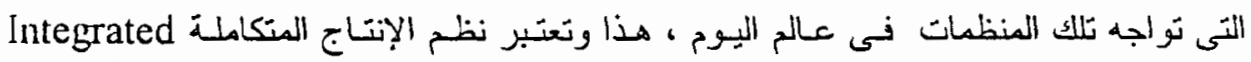

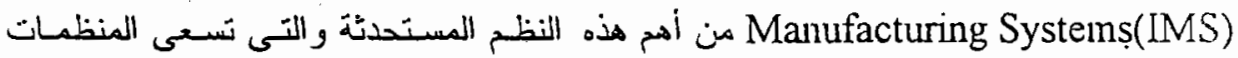

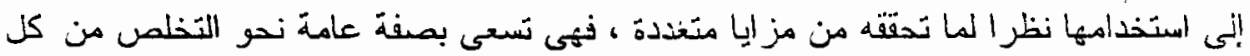

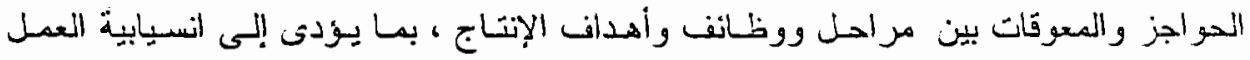
والإنتاج والتركيز عنى الأتشطة ذات القيمة المضافة (1) .

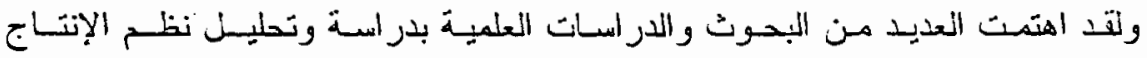

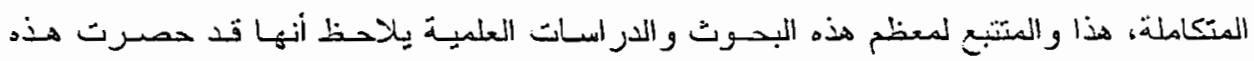

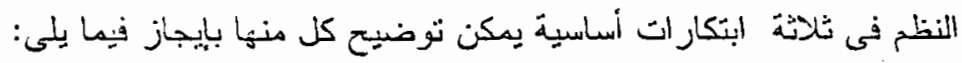

- 1

\section{Advanced Manufacturing Technology (AMT)}

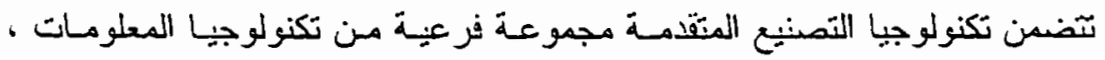

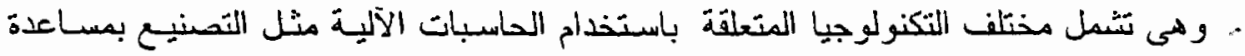

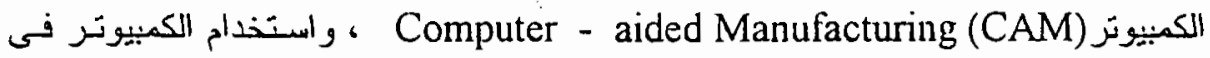
تخطيط العمليات Process Planning (CAPP) ، هذا ويمكن تجميع هذه التكنولوجيسا

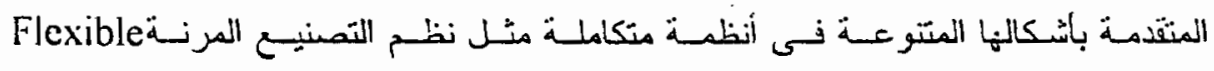
Manufacturing Systems (FMS) ( $(r)$ Computer- integrated Manufacturing Systems (CIM) 
Just - in - Time Production (JIT) الإنتاج فى الموعد بالضبط

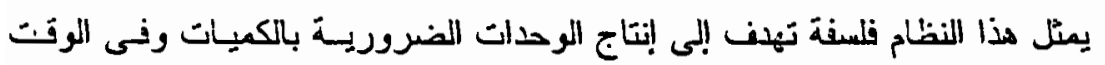

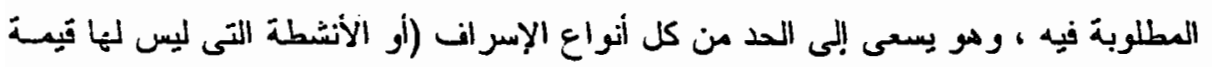

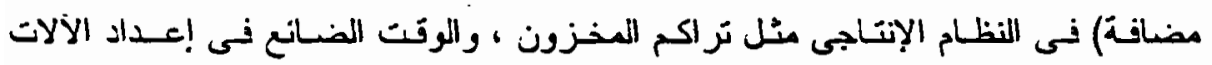

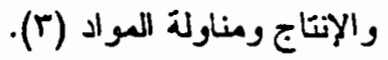

T- Total Quality Management (TQM) إدارة الجودة الشاملة

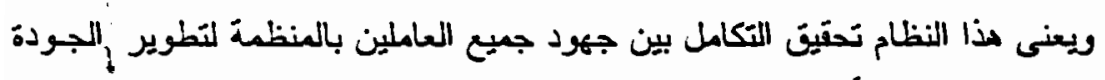

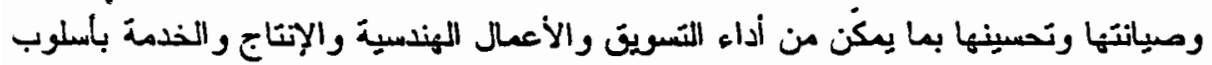

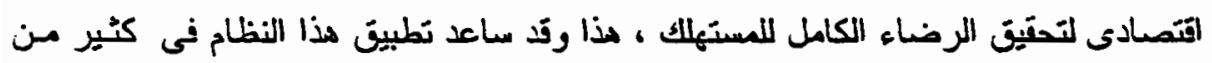

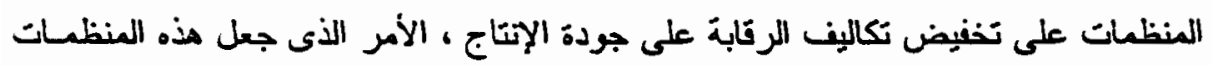

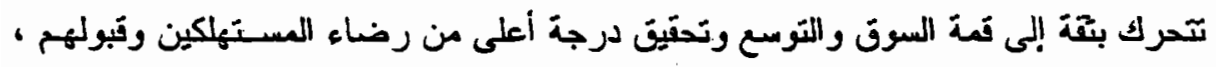

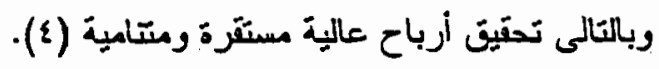

\section{الدراسات البسابقة:}

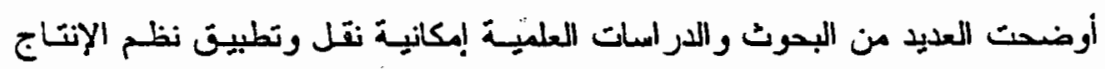

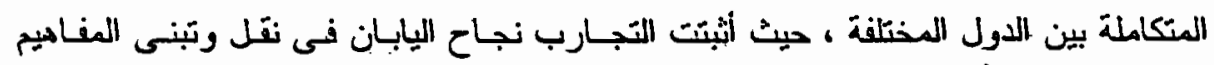

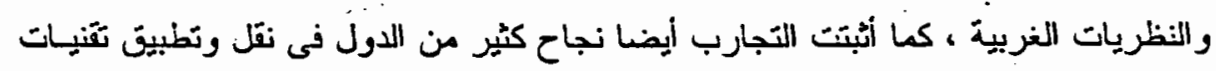
ونظم الإنتاج اليابانية إليهـا (0).

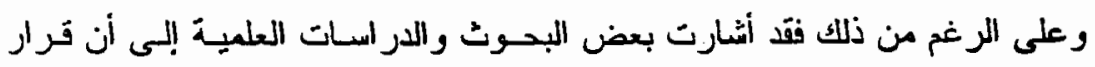

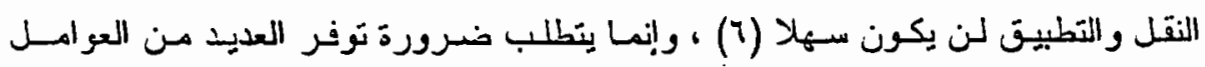

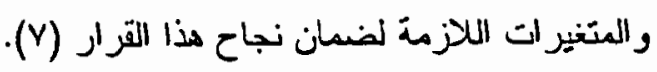

وفى هذا الصدد فقد كشفت العديد من البحوث والدراسات العلمية عن هــه العواملـ

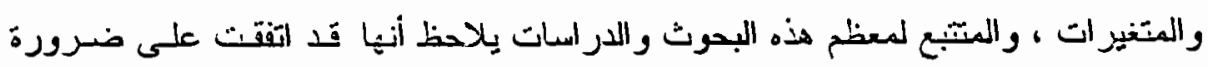

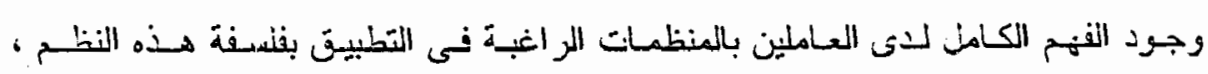

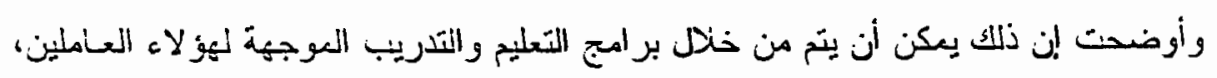

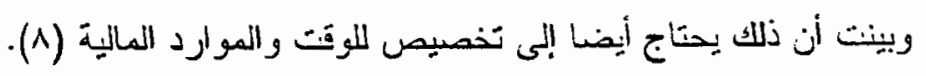


وفى هذا الإطلار ، فقد أوضحت إحدث الدراسـات العلميـة وجـود علاقهة ذات دلالهة

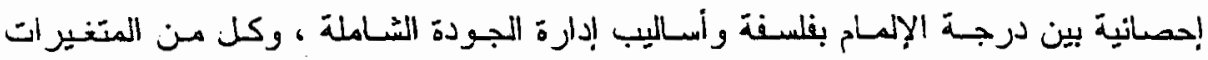

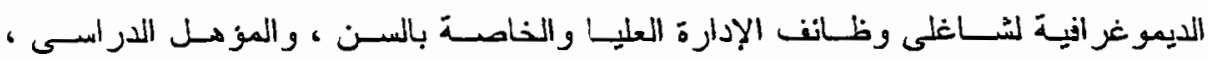

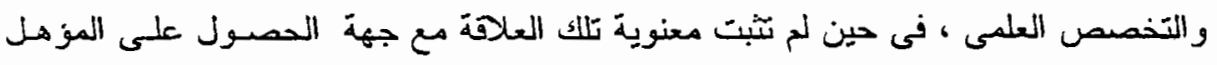

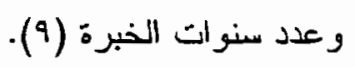

هذا كما أكدت بعض البحوث والدراسات العلمية على ضسرورة دعم وتاييد الإدارة

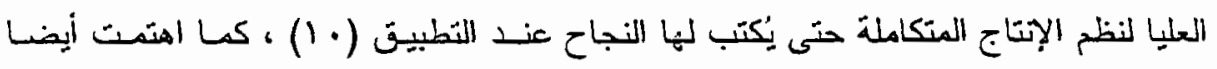

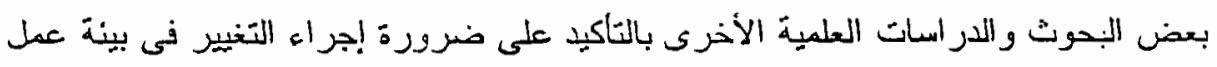

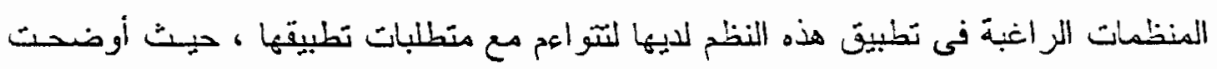

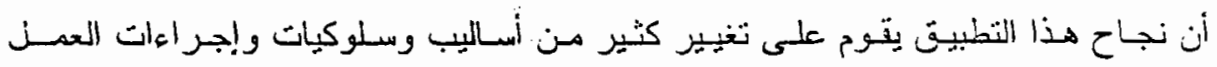
في هذه المنظمات (11) (11).

\section{شيكلة الدراسة:}

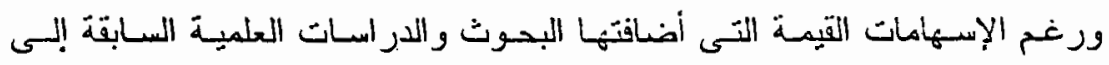

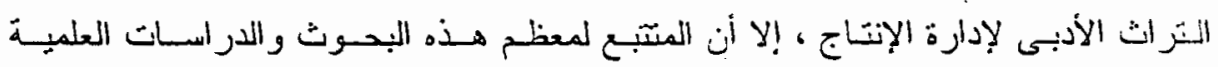

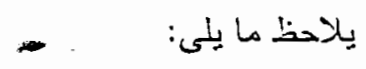

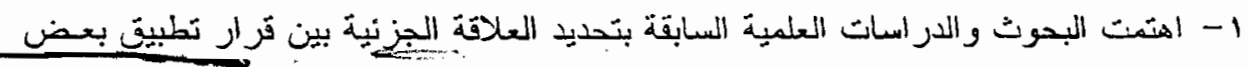

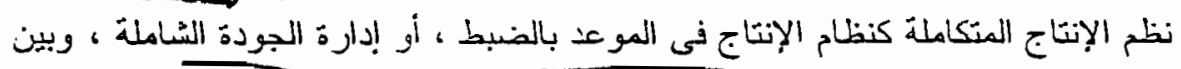

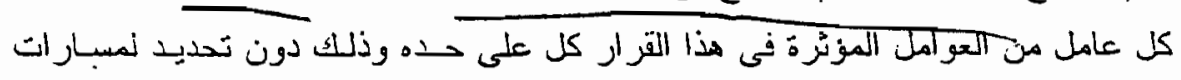

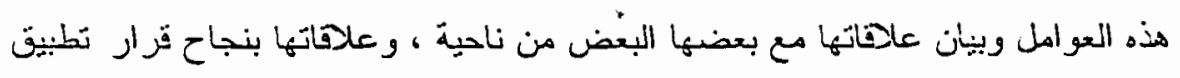

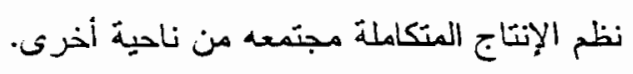

- استخدمت بعض البحوث والدراسات العلمية السابقة أسلوب النسسبة المنويـة لتحديـد مـدى

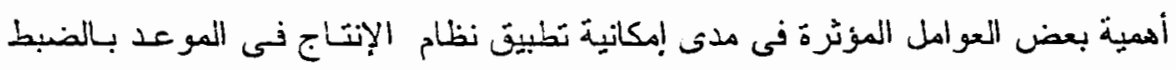

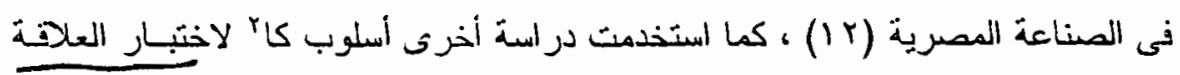

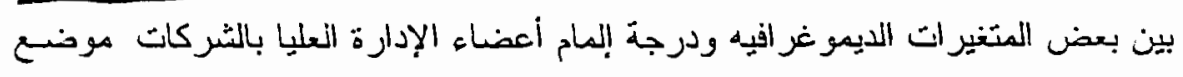

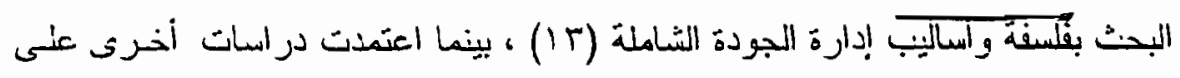

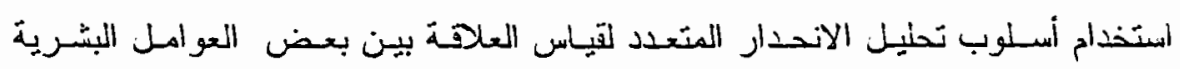
والخصائص الوظيفية ونظم الإنتاج المتكاملة (2 (1). 
ريتنَّ النباحث مع بعض البحوث والاراسات العلمية التى تزكلـ على أن أسلوب

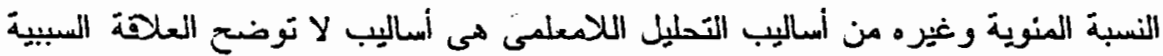

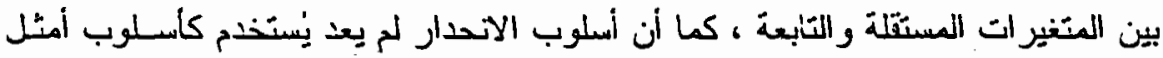

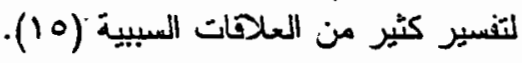

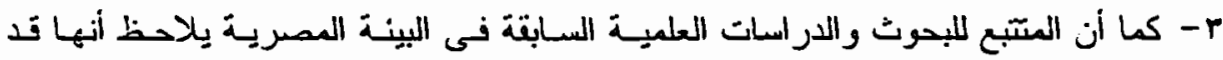

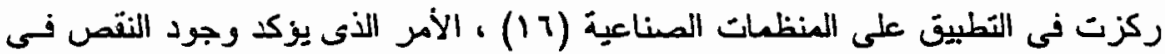

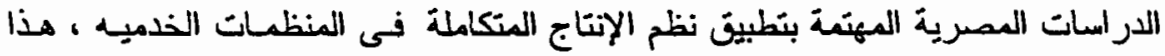
في نفس الوقت الذنى تزكد فيه الكثير من البحوث والار اسات والكتابات العلمِيسة الأجنبية على الاتجاد نحر تطبيق هذه النظم أو بعضها فى كثير من المنظمات الذدميه (IV).

\section{هدف الدراسة:}

وفى ضوء مشكلة البحث فإن هذه الدراسة تهدن إلى اقتراح نموذج سببى يتم هـن خلاله تحديد مسار ات العوامل المختلفة الموئرة فى نجاح قرار تطبيق نظم الإنتاج المنكاملة

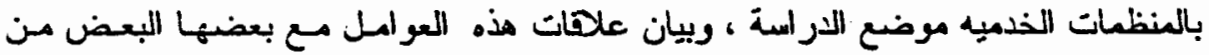

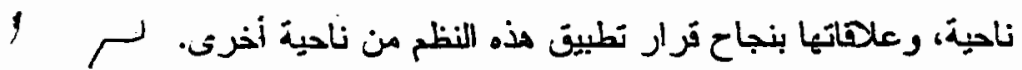

\section{الإهار الفكرى لبناء النهموذة الاقترج:}

هذا ومن خلال الدراسة المتانية والمتعمقة للبحوث و الدراسات العلمبية السابقة ، فقد

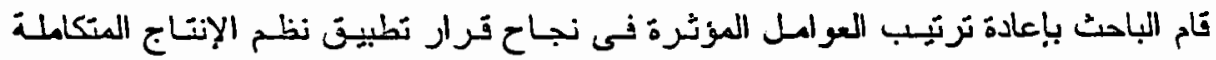

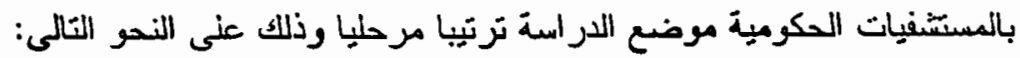

المرحلة الأولى: تـأييد أعضـاء الإدارة العليـا بالمستشفيات موضسع الدراسـة لتطبيت نظم الإتكاج المتكاملة فيهـا: حيث ينطلب الأمـر فى هذه المرحلة ضـرورة

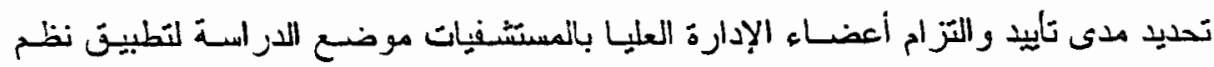
الإنتاج المنكاملة فينها.

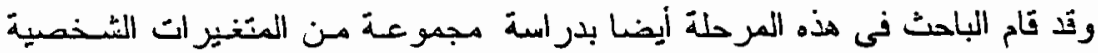

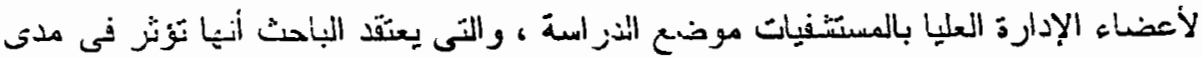

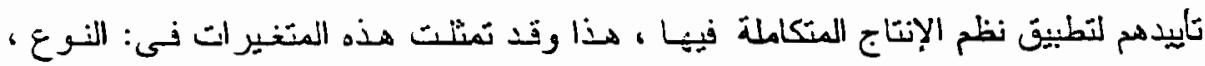
والسن، والمؤهل العلمى ، ومدة الخبرة بَى مجال العمل. 


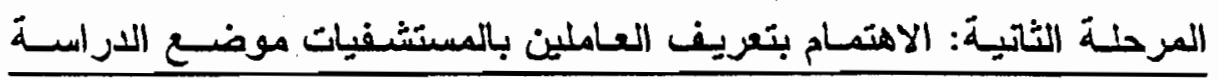

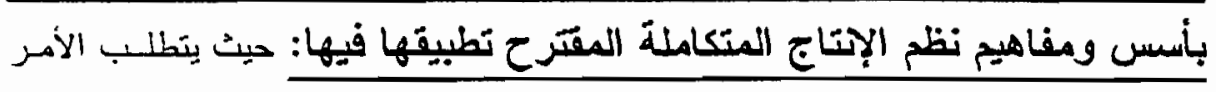

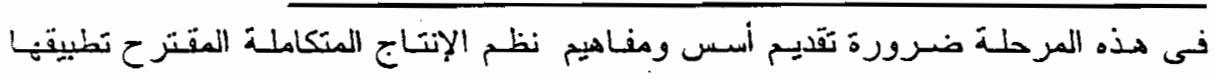

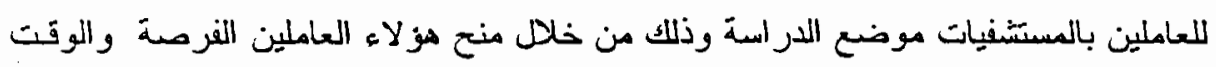

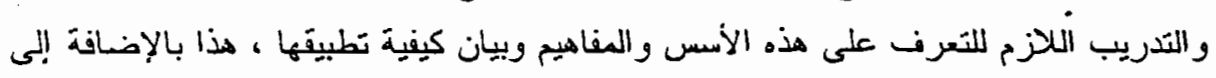
ضرورة تونير الموارد المالية اللازمة لتحقيق ذلك.

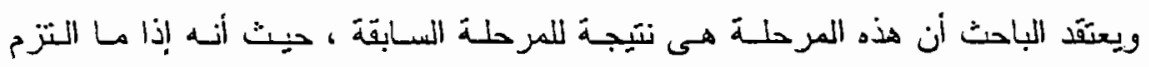

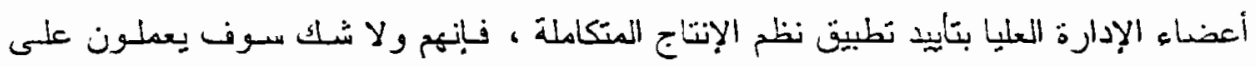

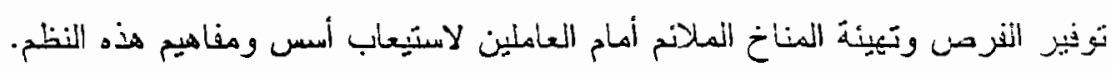

المرحلة الثالثة: إحداث التغيير في بيئة العهل بالمستتنفيات موضـع الاراسـة

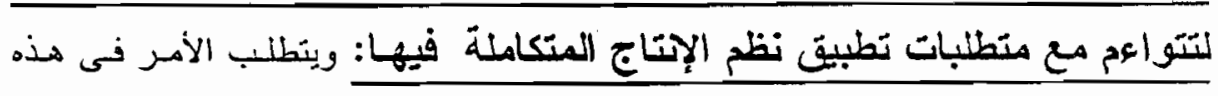

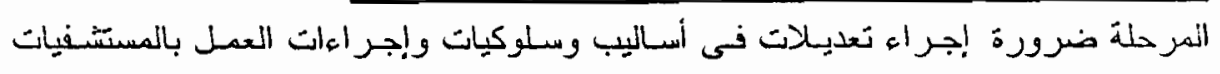

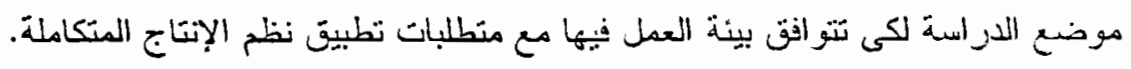

$+\infty$

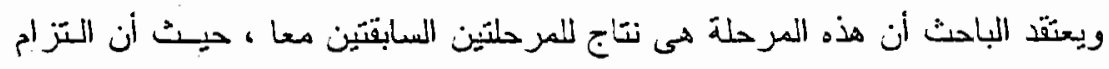

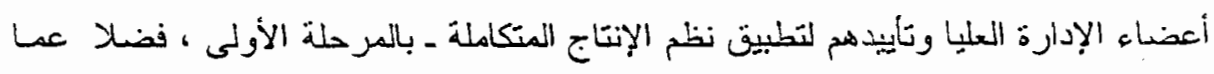

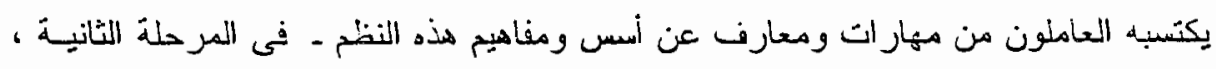

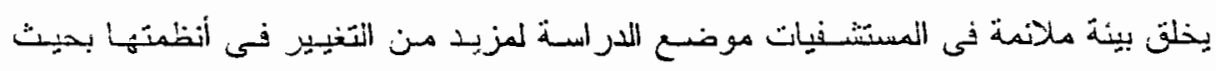

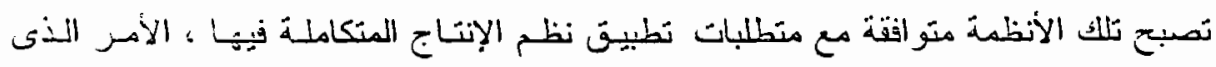
يتزب عليه بالتالى نجاح قرار تطبيق هذه النظم إذا ما تم اتخاذه في النهاية.

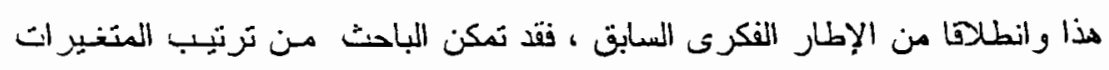

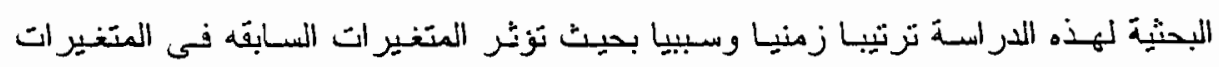

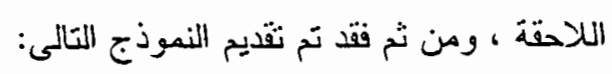



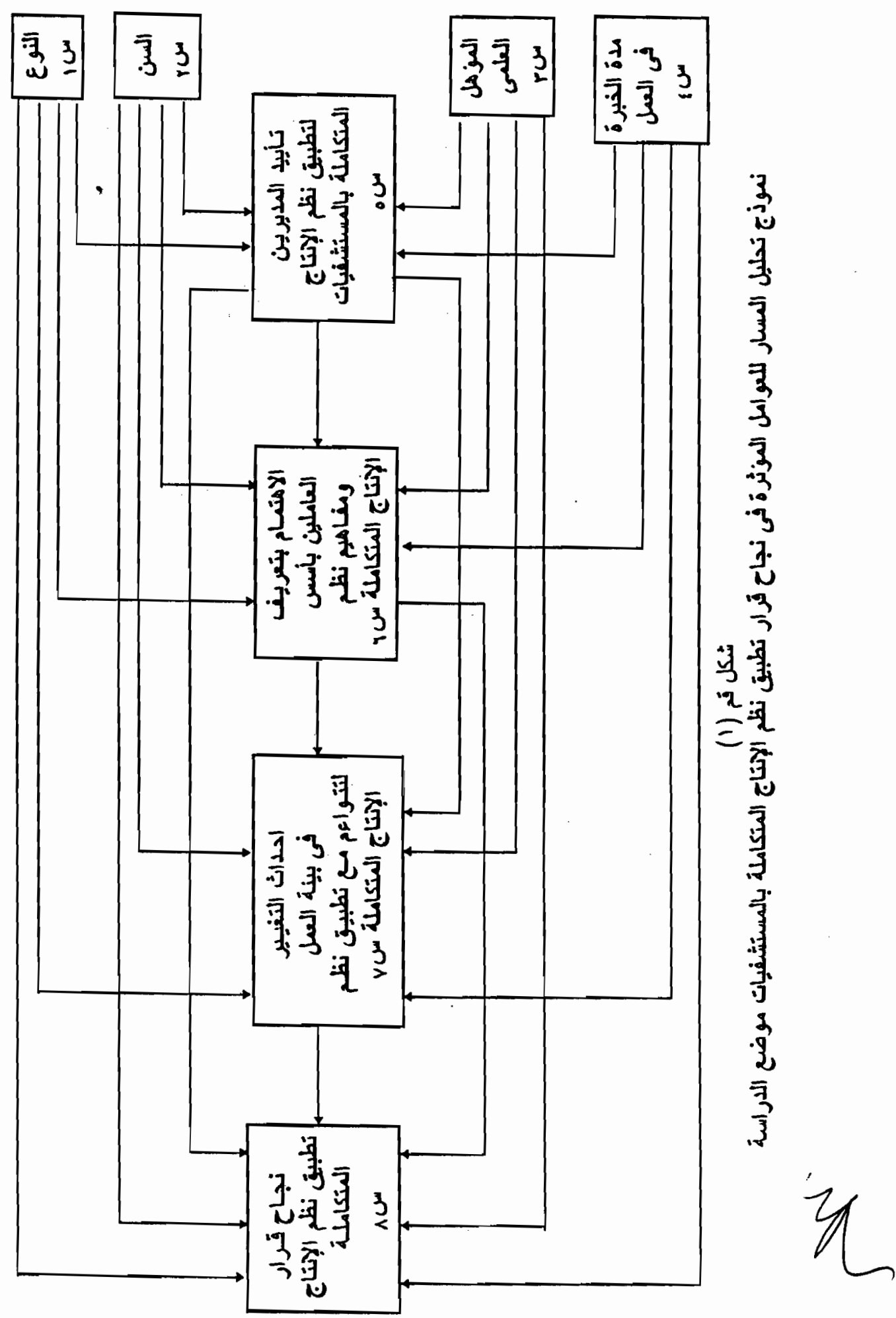


\section{فروض الدراسة:}

وفى ضوء نموذج تحليل المسار السابت ، فإن هذا البحث يقوم باختبار مسدى صحسة

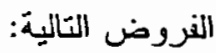

1- تسهم العوامل الخاصة بنوع مديرث المستشفيات موضع الدر اسة ، وسنهم ، وموهلهم

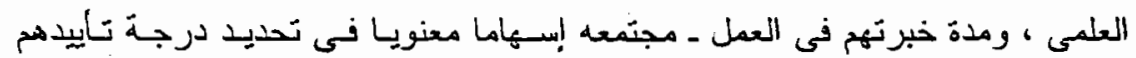
لتطبيق نظم الإنتاج المنكاملة فيها.

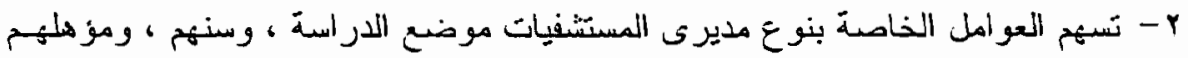

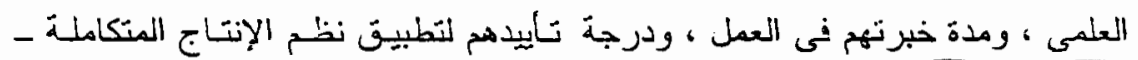

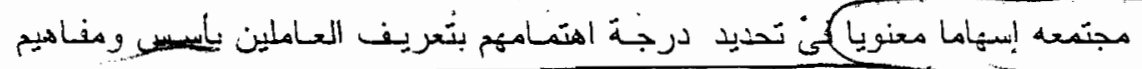
is r- تسهم العو امل الخاصة بنوع مديرث المستشفيات موضع الدر اسة ، وسنهج ، ومؤهلهم

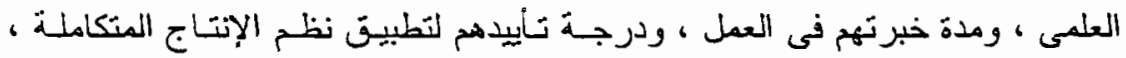

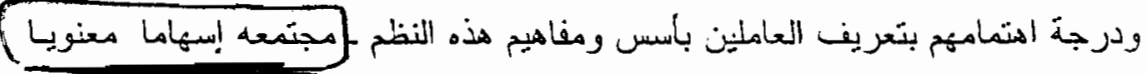
نى أحداث التغيير في بينة العمل لنتو اهم مع منطلبات تطبين نظم الإنتاج المنكاملة.

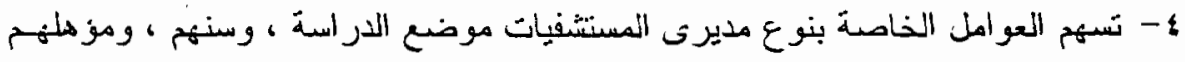

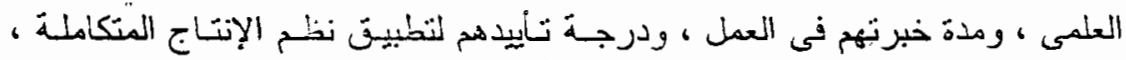

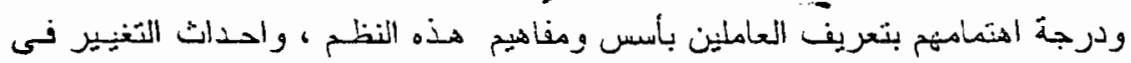

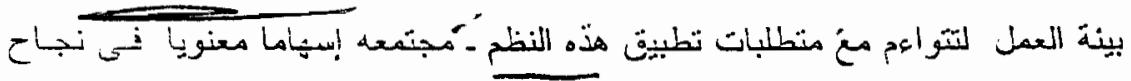

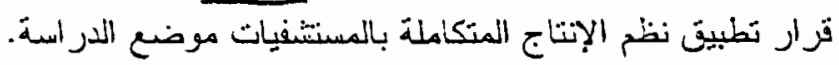

\section{أسلوب التحليل الإحصانيى المستخدم: أسلوب تحليل المدار:}

استخدم الباحث أسلوب تحليل المسار لاختبار مدى صحة فروض انتراسة باعتبـارد

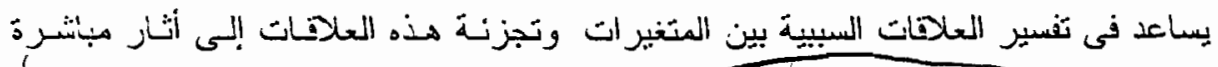
وغير مباشزة لكن متغير على الآخر (11). ريتطلب اسنَخدام أسنَب تحليل المسار ضرورة إجراء تحليل الاتحدار المتحسد بينز

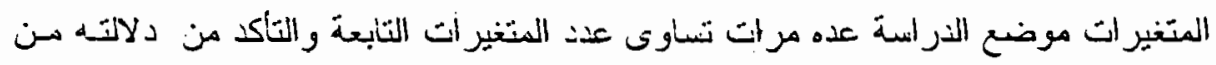

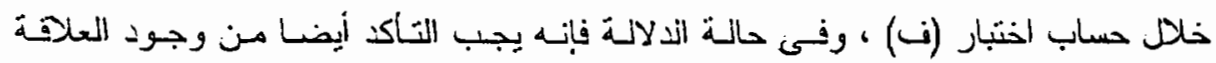




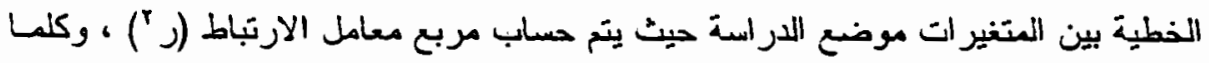

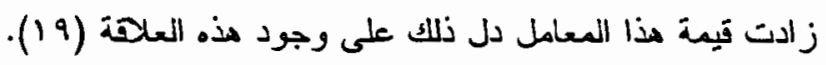

ويعتد أسلوب تحليل المسار في تحديد نوع ومقدار التأثيرات الناتجة عن العلحصات

بين المتغير ات التابعة والمستَلة موضيع الدر اسة على المعاملات التالية: - - معاملات الارتباط البسيط: حيـث يتم حساب معامل ارتباط بيرسـون بين قيم كل

$$
\text { متغيرين من المتغيرات موضع الدراسة (r. (Y). }
$$

r- معاملات السسارات التى توضع علاقَة المتفيرات المستقلة بـالمتغير التابع: ويتم

$$
\text { حساب هذه المعاملات باستخدام المعادلة التالية (r) (r): }
$$

الاندر ان المعيارى للمتغير المستقل

معاهل المسار = معامل الاتعدار الجزنى

الانحر ان المعيارى للمتغير التابع

$$
\text { r- قيمة (ت): وذلك لاختبار معنوية كل معامل انحدار فردى (rr). }
$$

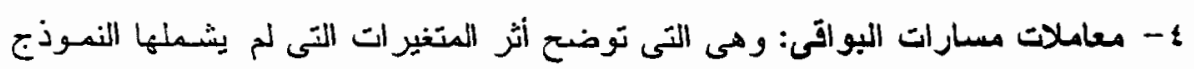

$$
\begin{aligned}
& \text { السيبى المقترح ، ويتم حسابها من واتع المعادلة التالية (rT): } \\
& \text { مأهل مسار البواقى = }
\end{aligned}
$$

هذا وقذ راعى الباحث عند استخدام هذا الأسلوب التأكد من توافر الشروط الخاصـة

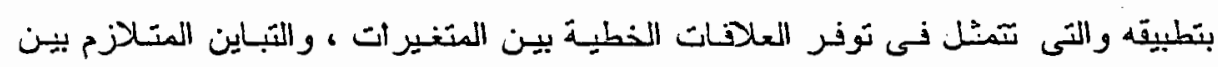

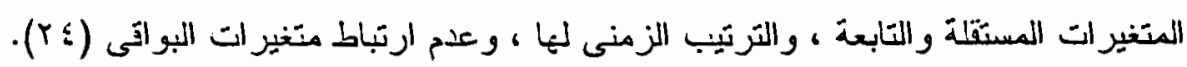

\section{أهميسة ألداسة}

تتبع أهمية هذا البحث من الناحية العلمية باعتباره بحاول بناء نمـوذج كمى يوضسح

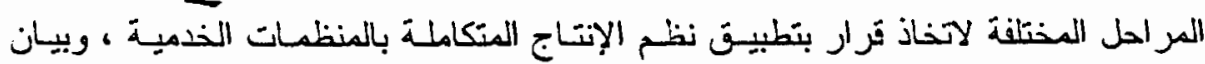

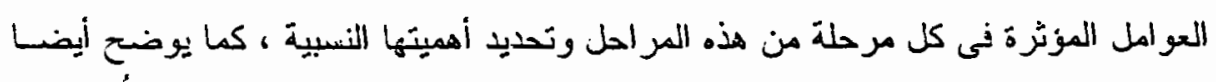

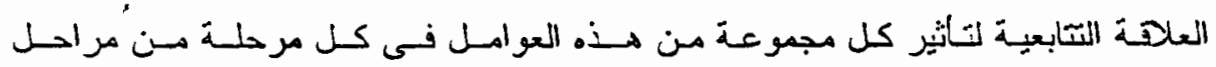
اتخاذ هذا القرار .

هذا من ناحية ، ومن ناحية أخرثى فإن أهية هذا البحث تمتذ إلى النواحى التطبيتية

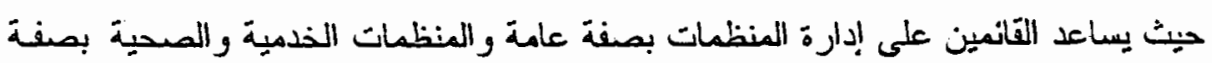


خامسة ـ وذلك بما يوفره من بيانات ومعلومات ـ على تفهي حقيقية العوامل المختلفة المؤترة فى مر احل اتخاذ قرار تطبيق نظم الإنتاج المتكاملة بمنظماتهم ، وتحديد الأهمية النسبية لكل

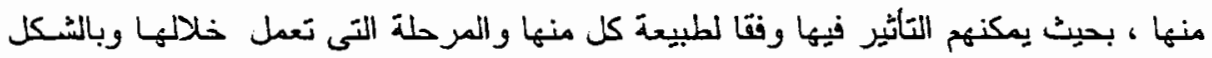
الذى يضمن لهم تطبيقا فعالا لنظم الإنتاج المنكاملة فى منظماتهم.

\section{أسلوب الدراسة:}

اعتمد الباحث عند إعداد هذا البحث على الأسلوبين التاليين:

$$
\text { 1- أسلوب اللدراسة النظزية: }
$$

تم باستخدام هذا الأسلوب وضع الإطار الفكرى لهذا البحث ، هذا وقد استمد الباحث

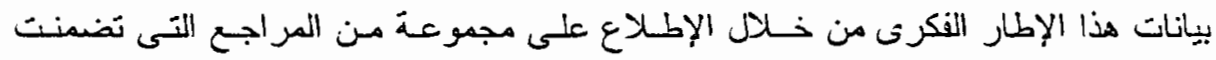
بعض الكتب والبحوث و الدراسات العلمية العربية والأجنيية.

$$
\text { r أسلوب الدراسة المبيأنية: }
$$

وقد استخدم الباحث هذا الأسلوب لاختبار مدى صحة فروض الدرامة ، هذا وقد تمـت الدراسة الميدانية على النحو التالى:

$$
\text { أ- مجتمع الدراسة: }
$$

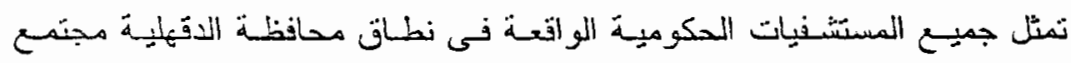

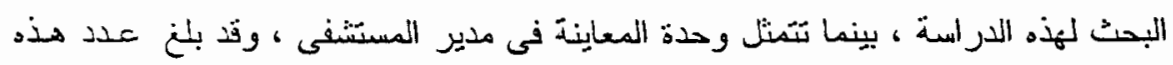

$$
\text { المستشفيات r r مسنسفى (ro) }
$$

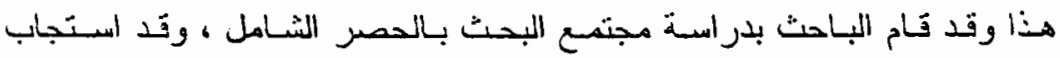

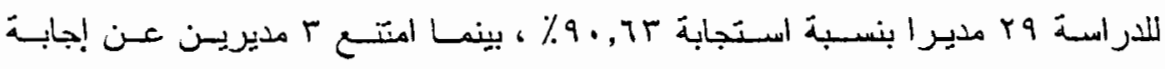

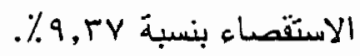

\section{ب- قائمة الاستقصاء واستيفاء بيانتاتها:}

قام الباحث بتجميع بيانات الدر اسـة الميدانية من مصادرهـا الأوليهة مسن مجتمـع

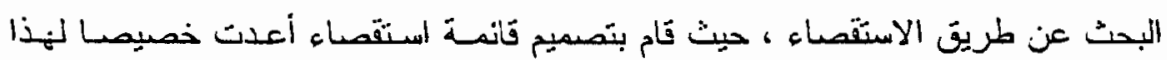

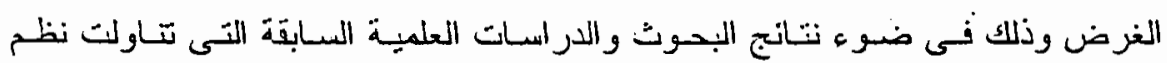

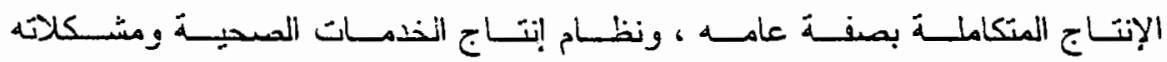




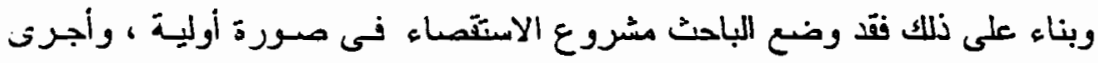

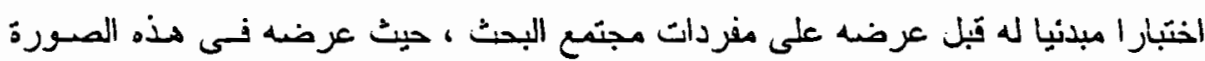

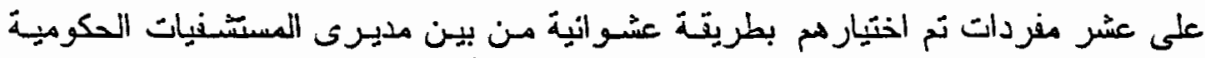

بمدافظة الدتهلية ، وذلك للتعرن على مدى فهمهم وتميز هم لعبار ات هذا الاستقصاء . وقد قام الباحث فى ضوء ملحوظنات هؤلاء المديرين بتعديل الاستقصاء وإعداده فى صورته النهانية متضمنا التسمين الرنيسيين التاليين: القسم الأول: اشتمل هذا القسم على أربعة أسنلة غطى كل سؤل منها مرحلة من مراحل

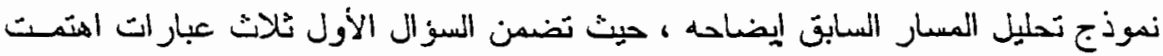
بتحديد مدى تاييد مذيرين المستشفيات موضع الدراسة لتطبيق نظم الإنتاج المنكاملة فيها،

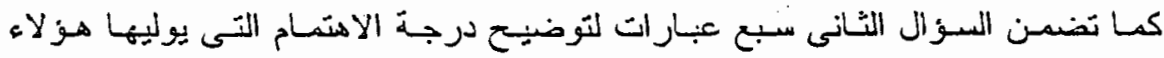

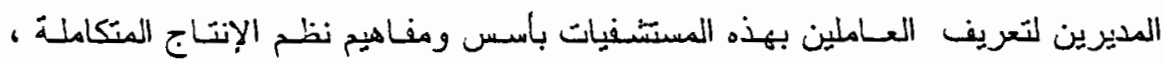
واشتمل السؤال الثالث على تسع وعشرين عبارة تعلقت بـالتغير ات الممكن إحداثها في

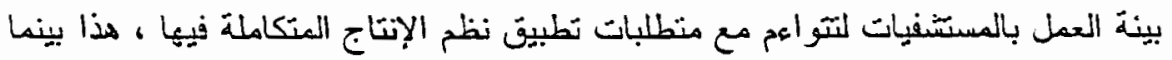

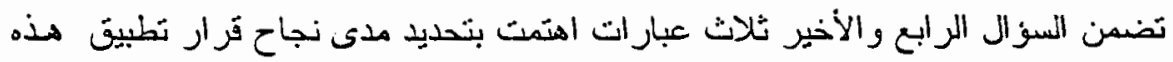
النظم بالمستّفيات موضع الدر استة.

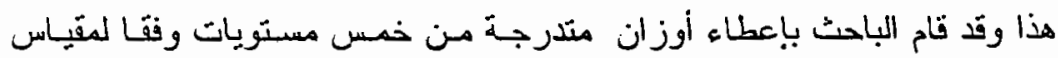
ليكرت لكل عبارة من عبار ات الأسنلة الأربعة السابقة.

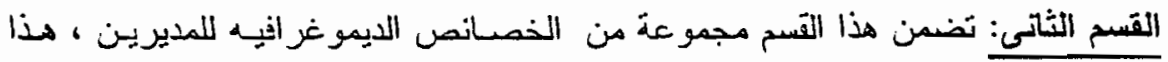

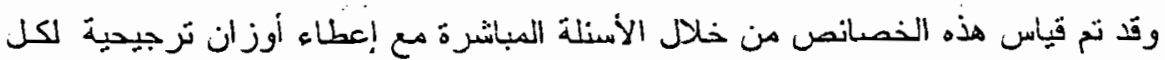
منها ، هذا وفد تمثلت هذه الخصانص فئس فيما يلى:

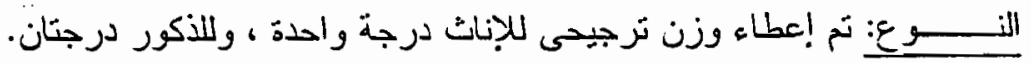

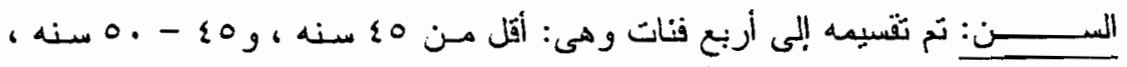

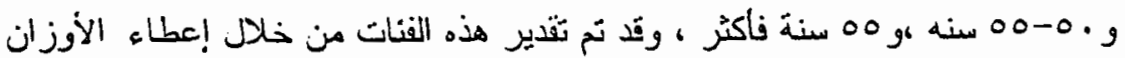

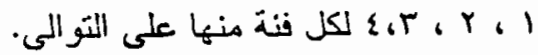

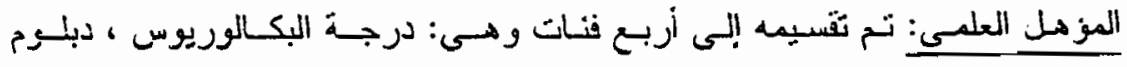

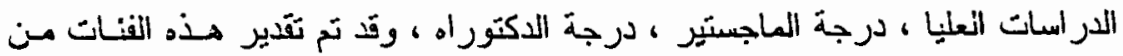

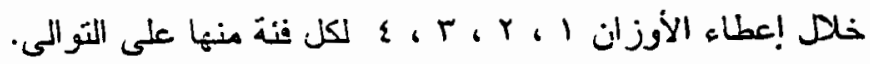




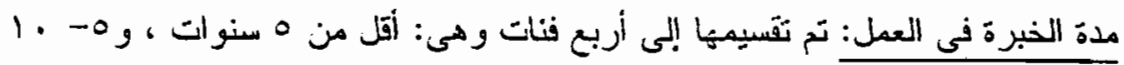

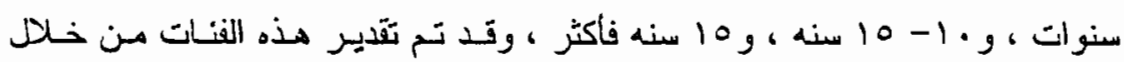

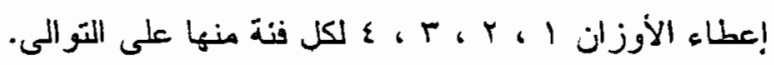

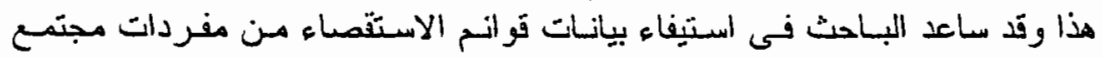

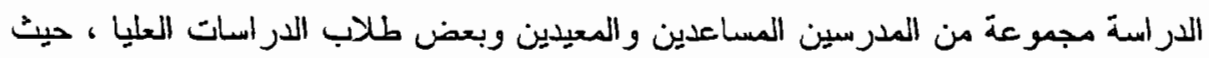

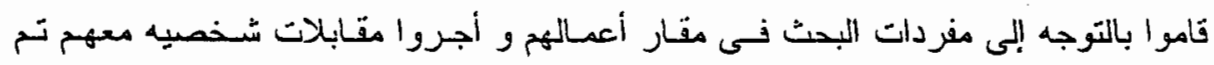

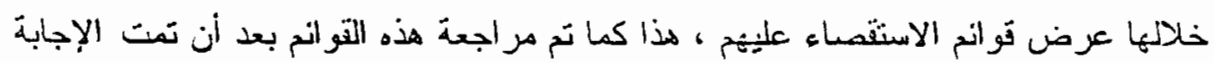
على أسنلتها ثم تم تفريغها فى جداول خاصة تصلح لإجراء التحليل الإحصانى عليها.

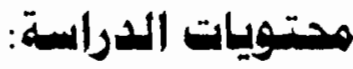

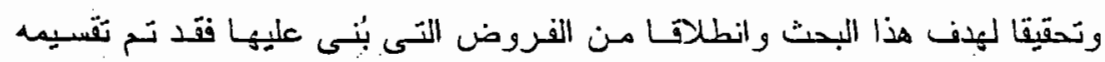
ليشمل در أسة الموضنو عات الرنيسية التالية:

أولا: العوامل المؤترة فى درجة تأييل مليرى المستشفيات موضـع الدراسة تتطبيت نظم الإتتاج المتكاملة فيها.

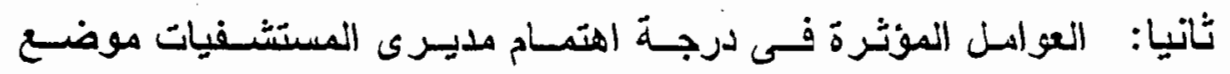
اللار استة بتعريف العاملين فيها بأسس ومفاهيم نظم الإنتاج المتكاملة.

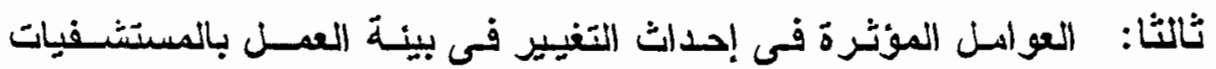
موضع الار اسة لتتـواءم مـع متطلبـات تطبينق نظم الإنتـاج المتكاملـة فيها.

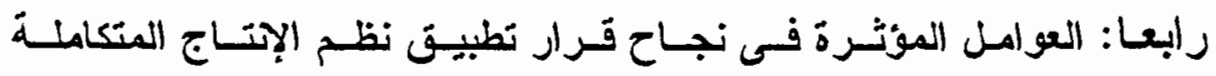
بالمستشفيات موضع الدرالمة. خامسا: التتائج والتوصيات. 


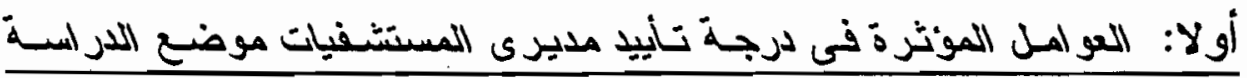 لتطبين نظم الإنتاج المتكاملة فيها:}

يقوم الفرض الأول من فروض الدراسـة على أن العوأملـ الخامسة بنوع مديرى

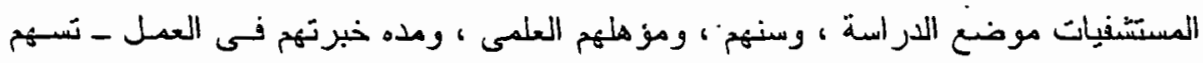

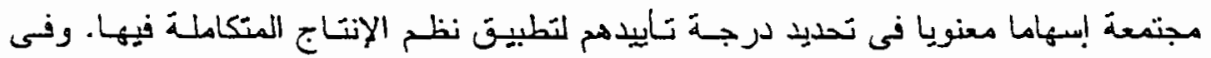

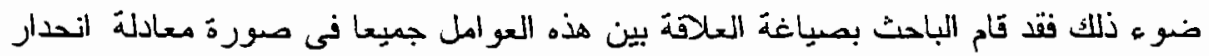

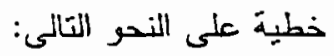

$$
\text { m }
$$

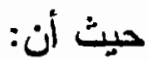

م معاملات المسار فى صورتها المعيارية.

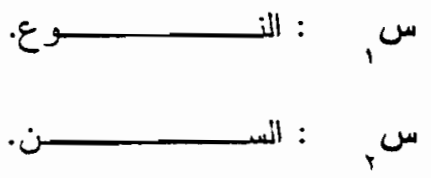

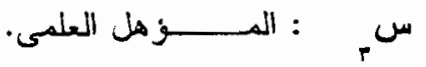

سل : مدة الخبرة فى العمل.

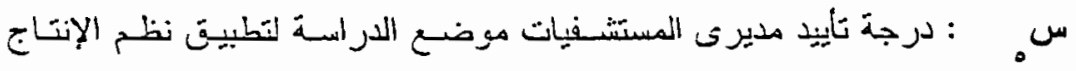

المتكاملة فيها (المتغير التابع).

ق. : الخطا فى تنسير المتغير التابع.

ويوضح الجدول رقم (1) نتائج تحليل هذه العلاقة: 


\section{جدول رقم (1)}

نتاثج تحليل السـار للعوامل المؤثرة في درجة تأيِيد مديرى المستشفيات موضع الاراسة

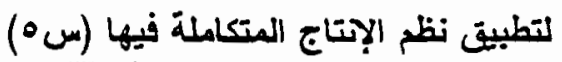

\begin{tabular}{|c|c|c|c|c|}
\hline 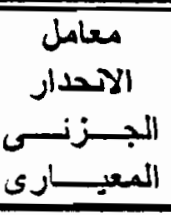 & 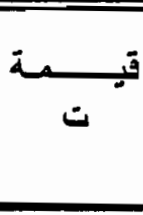 & 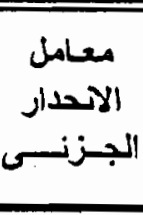 & معامل الارتباط & البِـــان \\
\hline$\cdot, Y q$ & $1,7 v$ & $\cdot,\{\varepsilon$ & $\cdot, r \leq$ & | 1- النو \\
\hline$\cdot . \cdot r$ & $\cdot, r_{\bullet}-$ & $\cdot, \cdot 7$ &..$v$ & r- السن (س,) \\
\hline$\cdot, \leqslant$ & er,it & $T, T$ & $\cdots, \leq \Lambda$ & T- المؤهلـل العلمـــى \\
\hline$\cdot, Y_{I}-$ & $1,1 Y-$ & $\cdot, Y q-$ & $\cdot, \cdot 1$ & ؟- مسدة الخـبرة نسى \\
\hline \multicolumn{3}{|c|}{ •. معنوية عند 1... } & \multicolumn{2}{|c|}{ معامل التحديذ (رد") = . rr, • } \\
\hline \multicolumn{3}{|c|}{ • معنهية } & $\bullet, q \circ:=$ & لمسة ن \\
\hline
\end{tabular}

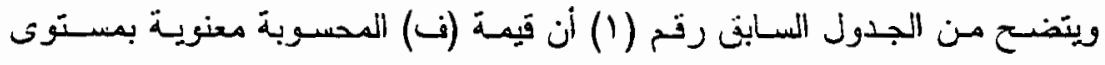

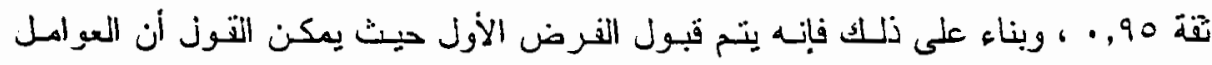

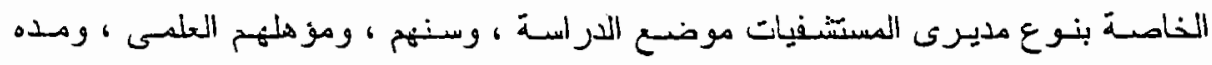

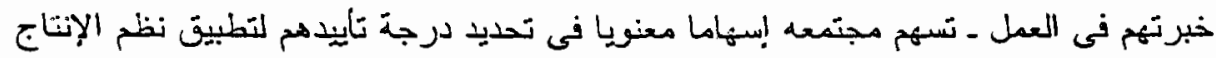
المنكاملة فيها.

و على الرغم من ذلك فإن قيم (ت) المحسوبة تتسير إلمى وجسود متغير واحسد يسـيخج

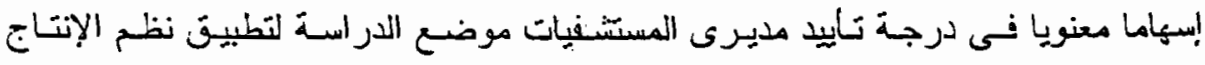

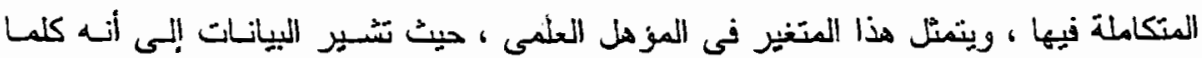

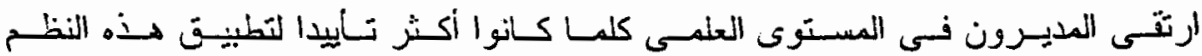
المستحدثة بمسنتشفياتهم.

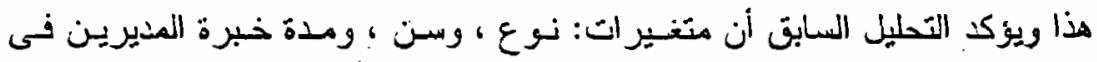

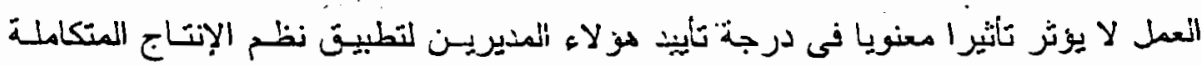

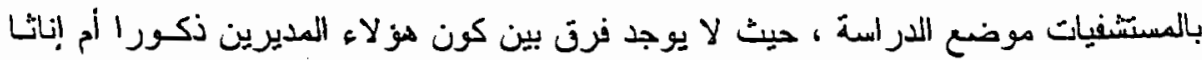


وبين درجة تاييدهم لنطبيق هذه النظم بمستتفياتهم ، كما لا يوثر أيضا صغر سنهم أو كبره

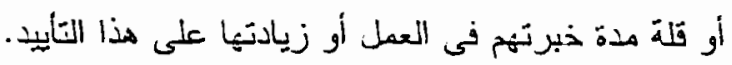

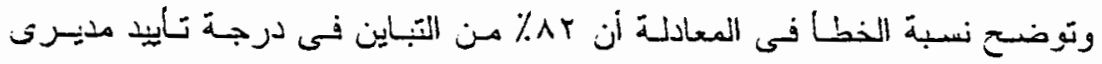

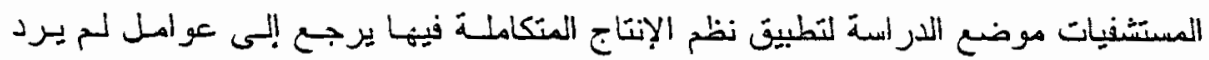
ذكر ها بالنموذج.

وفى ضوء ذللك فبن النتيجة النهانية لتحليل المسار فى هذه الخطوة يمكن توضيحهبا

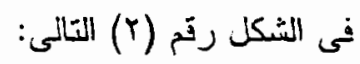

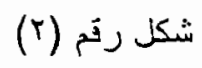

تحليل المسار للعوامل المؤثرة فى درجة تأييد مديرى المستَففيات موضع الدراسة لتطبيت نظم الإنتاج انمتكاملة فيهيا

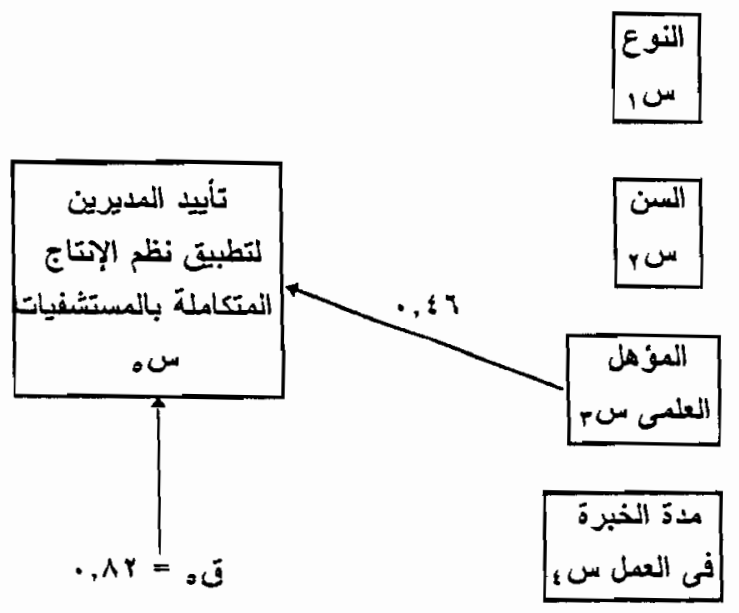

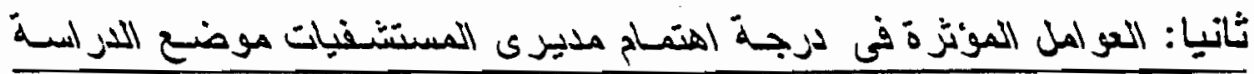

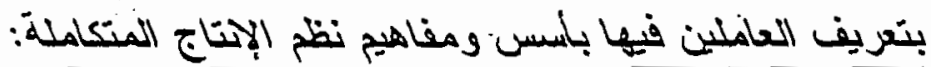

ويقوم الفرض الثانى هن فروض الدراسة على أن العوامل الخاصسة بنوع مديرى

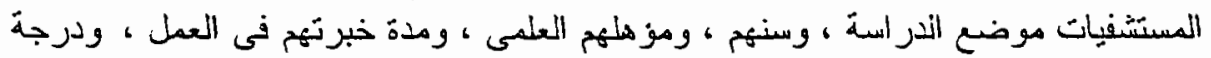

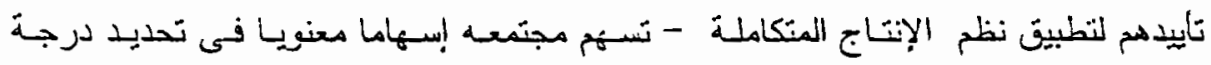

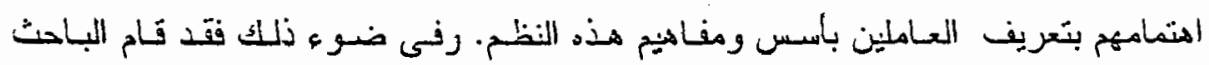
بصياغة أنعلافة بين هذه العواهل جميعا فى صورة المعادلة الذطية. التالية:

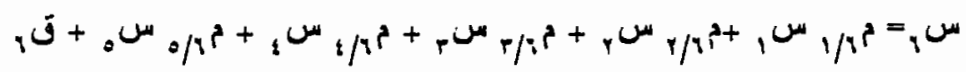




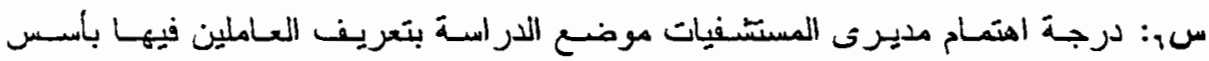
ومفاهيخ نظم الإنتاج المنكاملة (المتغير التابع). قر،: الخطا فى تنسير المتغير التابع. ويرضح الجدول رقم (r) نتأج تحليل هذه العلقة:

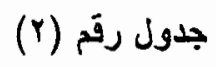

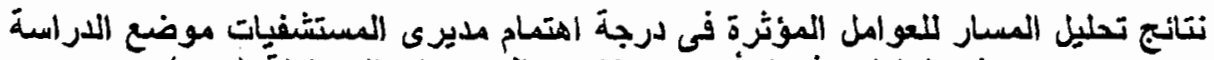

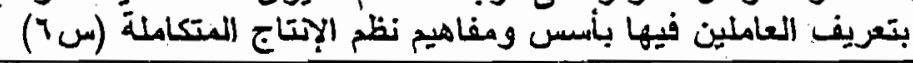

\begin{tabular}{|c|c|c|c|c|}
\hline الجزنى المعيذزي & تيمــــة & معالجل الآحداز & معالمل الارتباط & 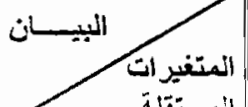 \\
\hline 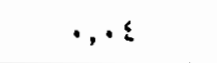 & - & $\cdot, \cdot 1$ & צו, & 1- النوع (س) \\
\hline ,.,7- & $\cdot, \vdots \cdot-$ & $\cdot, 1 \gamma-$ &., .9 & r- النسن (سr) \\
\hline$\cdot, \cdot 1$ & •, $\leqslant \uparrow$ & $\cdot, 79$ & •, Yr & T- المونل العلمى \\
\hline$\cdot, \cdot 1-$ & $\cdot, \leqslant \Lambda$ & $\cdot, 1 \Lambda^{-}$ & $\cdot, T$ & 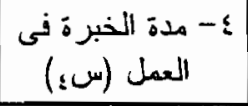 \\
\hline., 01 & $* r, . .1$ & $\therefore 9$. & • & 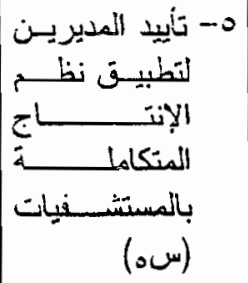 \\
\hline & معنوية & & 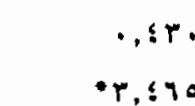 & 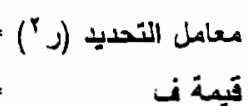 \\
\hline
\end{tabular}

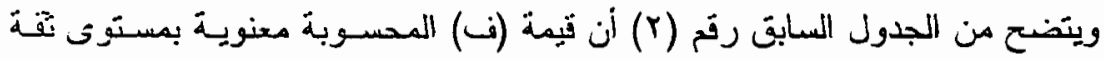

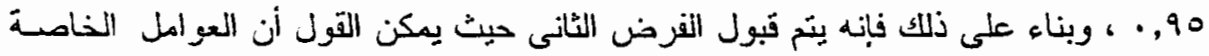

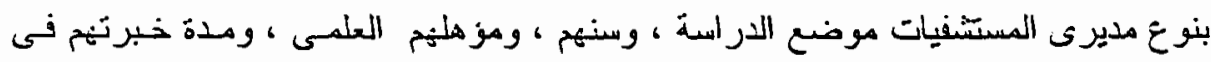

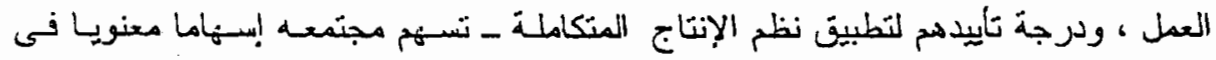

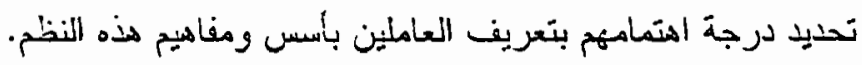

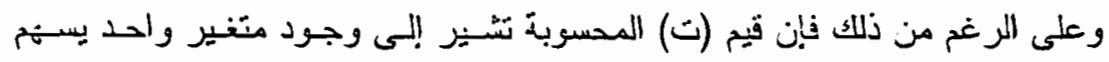

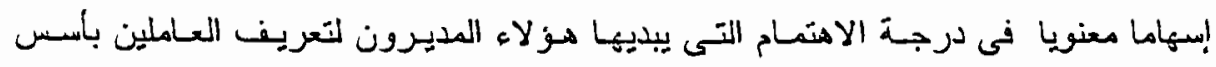

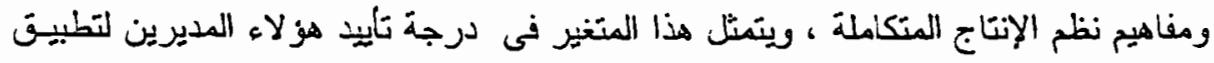




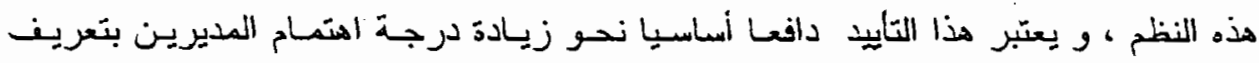

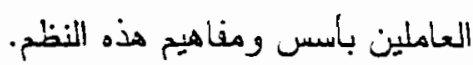

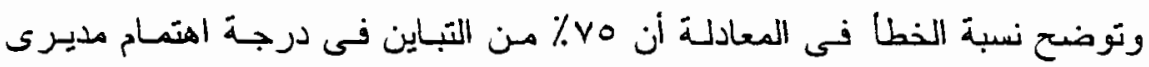

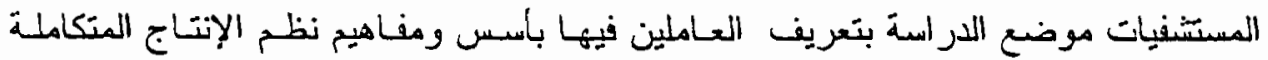

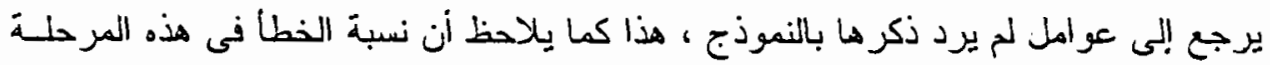
اقل من نسبة الخطا فى المرحلة السابقة.

وفى ضوء ذلك فان النتيجة النهائية لتحليل المسار في هذه الخطوة يمكن توضيحنبا.

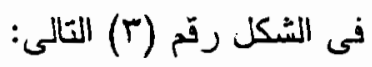

$$
\text { (r) شكل رقَم }
$$

تحليل المسار للعوامل المؤنزة فى درجة اهنمام مديرى المستشفيات موضع الدراسة بتعريف العامنين فيها بأسس ومفاهيم نظم الإتتاج المتكاملة

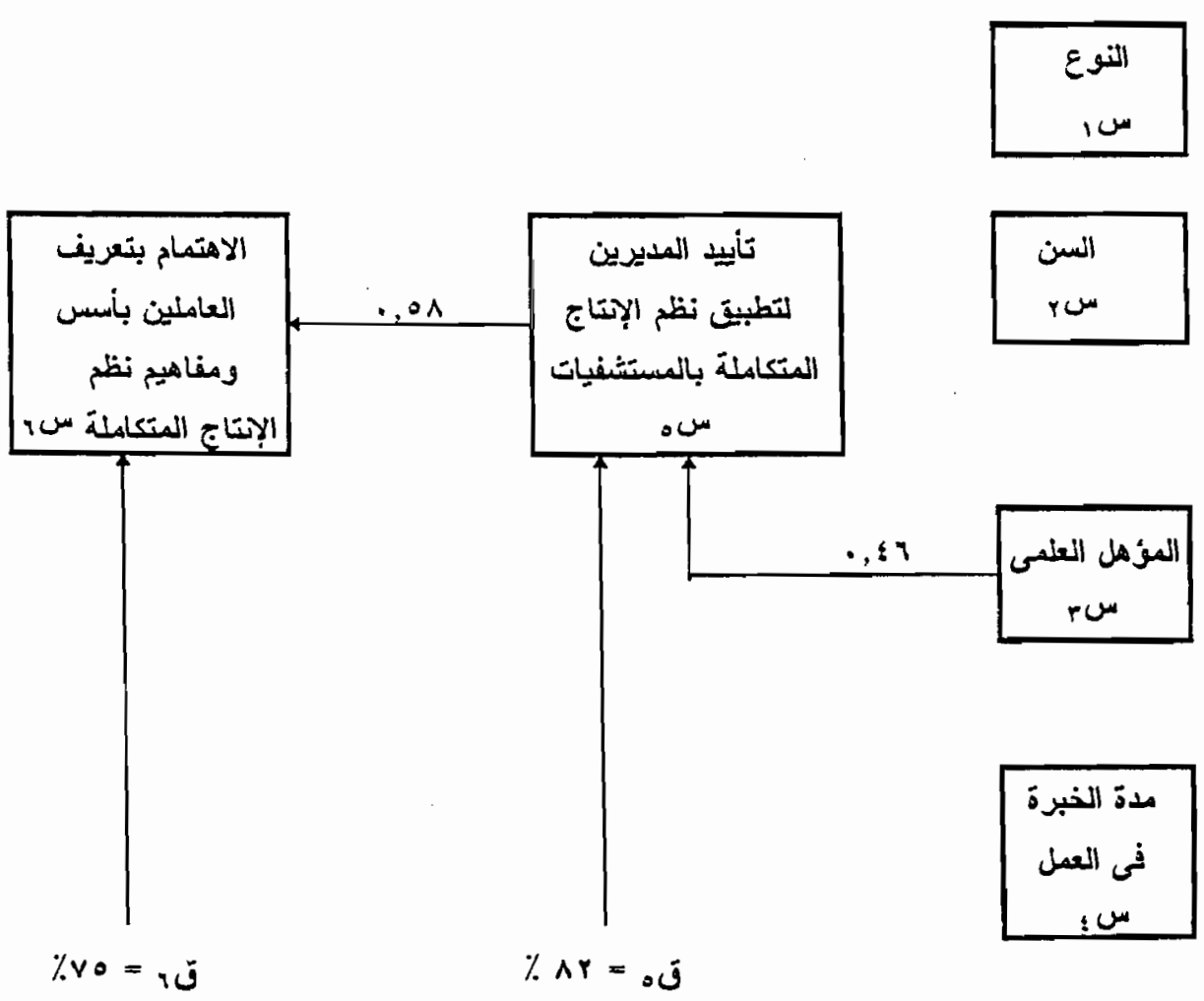




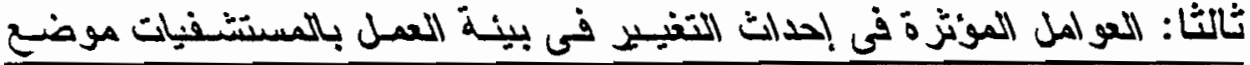

\section{الار اسة لتتو ائم مع منطلبات تطبيت نظم الإنتاج المتكاملة فيها:}

ويقوم الفرض الثالث من فروض الار اسة على أن العواملـ الخاصسة بنوع مديرى

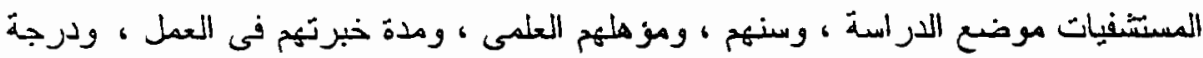

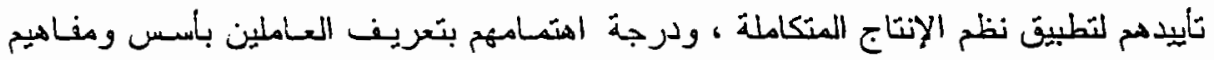

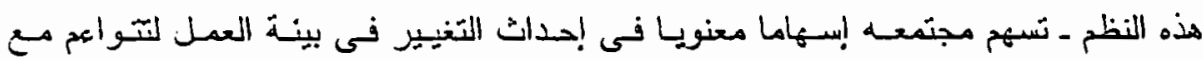

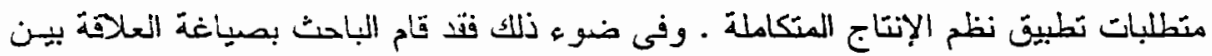

هذه العو امل جميعا في صورة المعادلة الخطية التالية:

$$
\text { m }
$$

حيث أنم:

سم: أحداث التغيير في بينة العمل بالمستشفيات موضع الدراسة لتــواءم مـع منطلبـات تطبيتق

نظّم الإنتاج المتكاملة (المتغير التابع).

قى: الخطا في تنسير المتغير التابع.

ويوضتح الجنول رقت (r) نتانج تحليل هذه العلاقة:

جدول رقم (r) (r)

تتائج تحليل المسار للعو امل المؤثرة في إحداث التنيير في بينة العمل بانمستشفيات رون

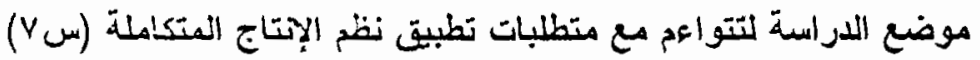

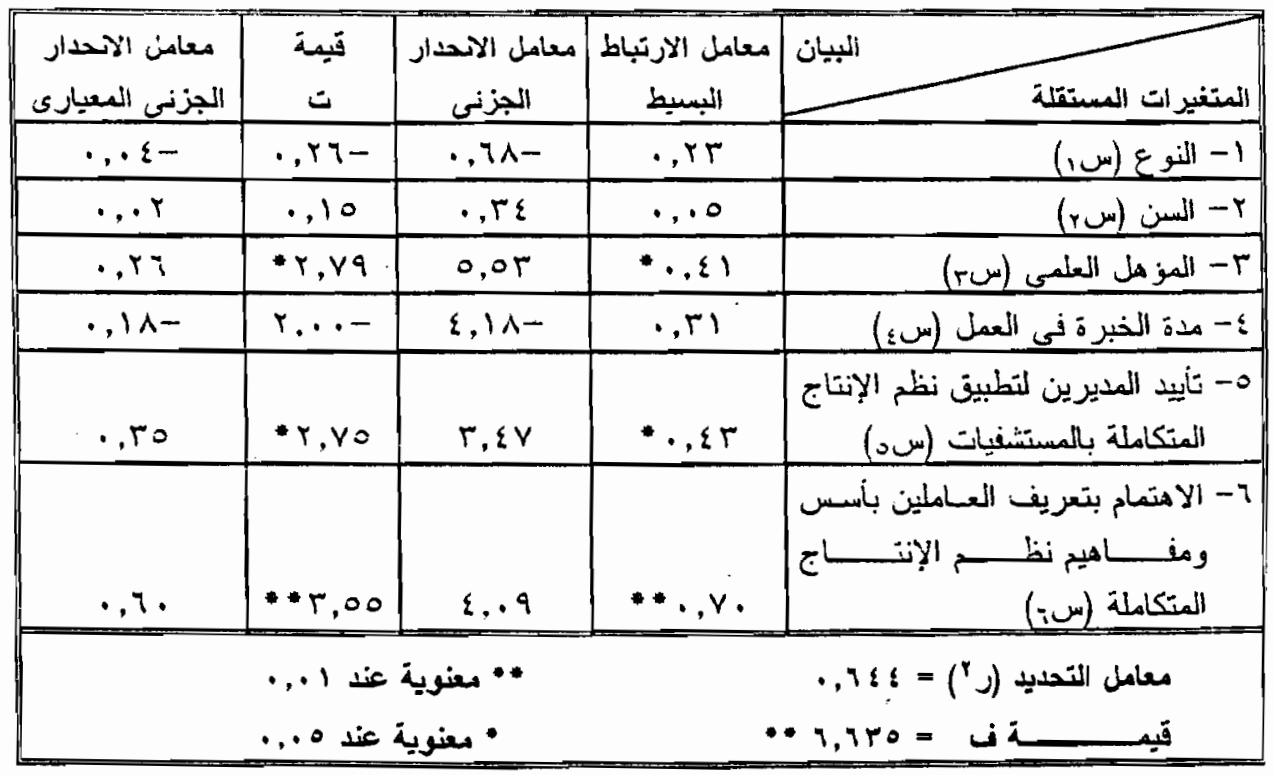




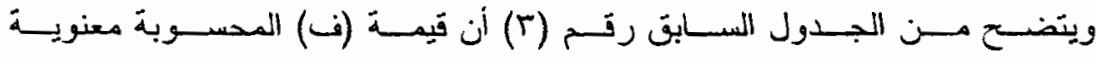

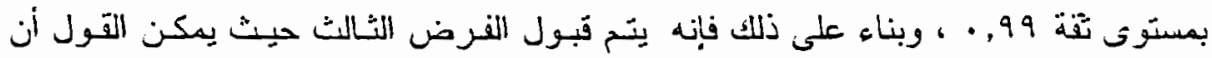

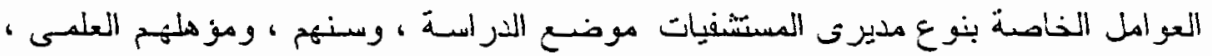

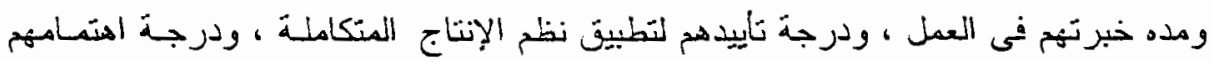

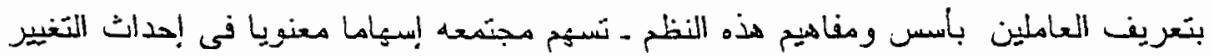
فى بينة العمل لتو اهم مع منطلبات تطبيق نظم الإنتاج المتكاملة.

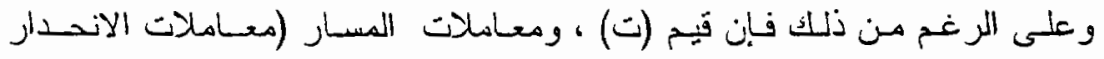

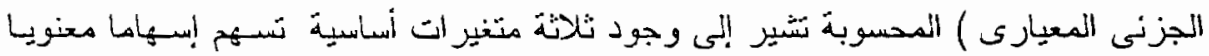

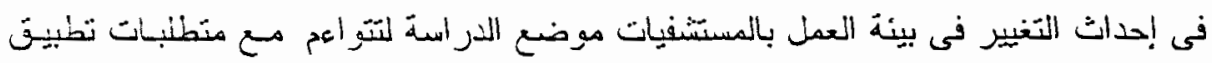

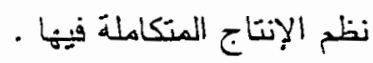

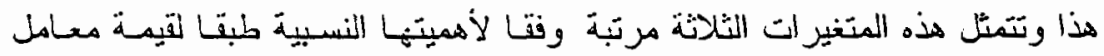

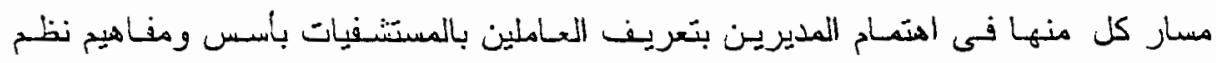

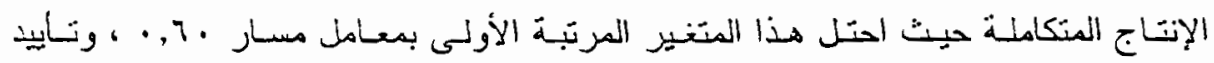

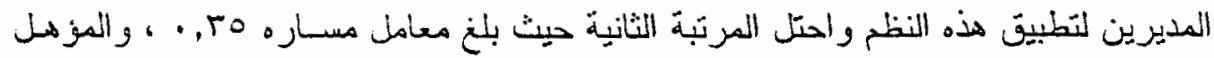

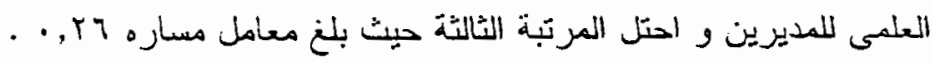

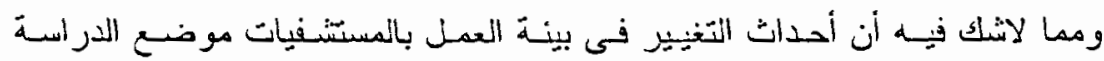

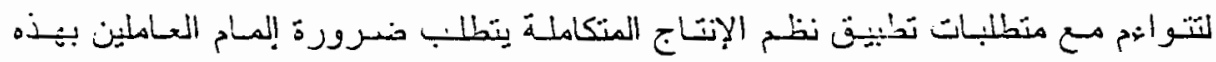

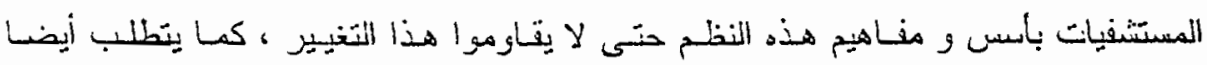

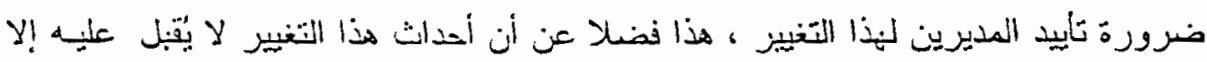

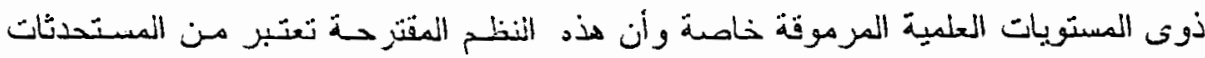

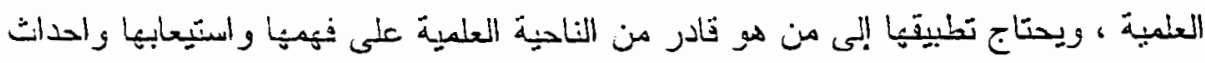

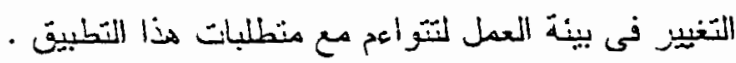

وتوضح نسبة انخطل أن هنائ ، ح٪ من التباين فى درجة إحداث التغيير في بينة

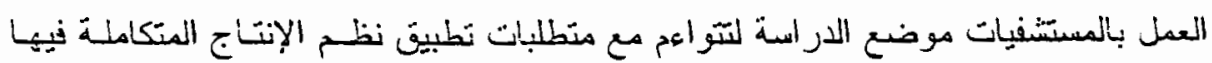

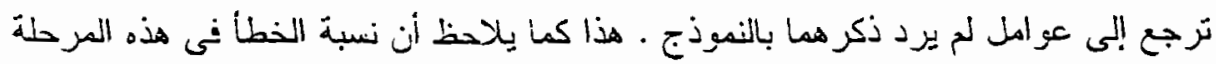

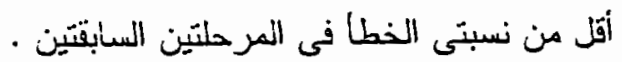

وفى ضوء ذللك فلبن النتيجة اللنبانية لتحليل المسار فى هذه الخطوة يمكن توضيحها فى الثكل رثم (ع) التالى 


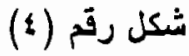

تحليل المسار للعوامل المؤثرة في إحداث التغيير فى بيئة العمل بالمستشفيات

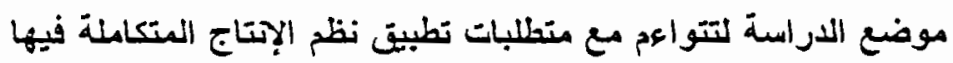

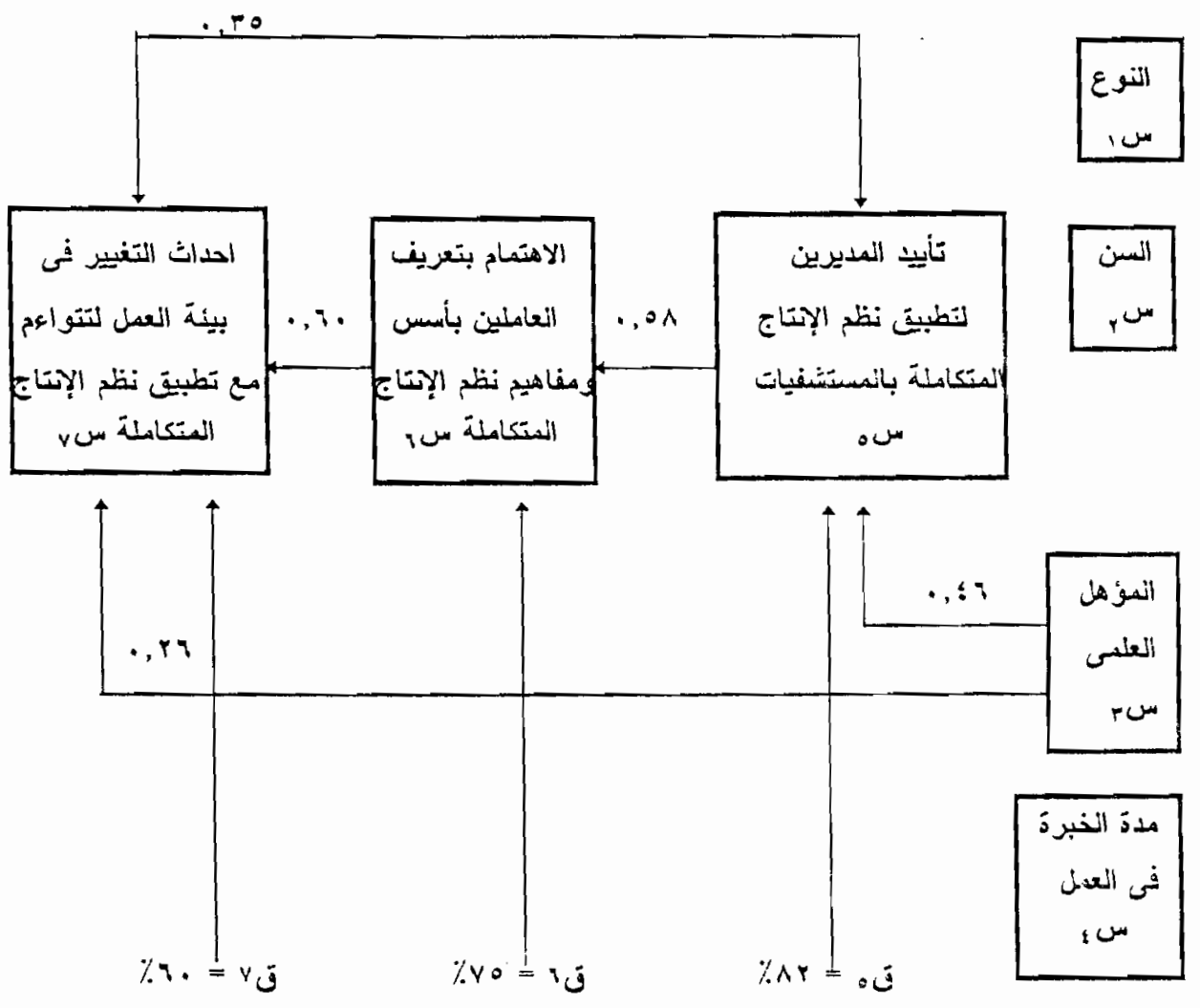

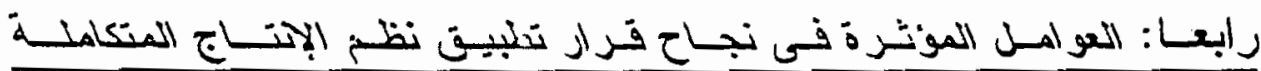
بالمستشتفيات موضنح اللار السة :

ويقوم الفرض الر ابع من فروض الدراسة على أن العواهـل الخامـة بنـوع مديـرى

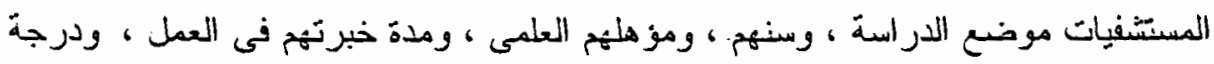

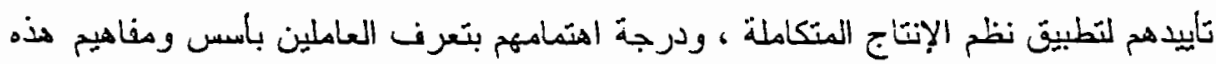

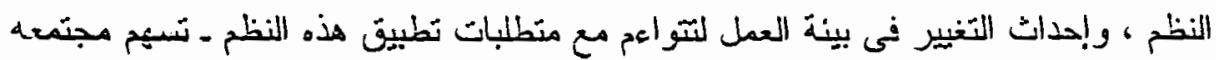

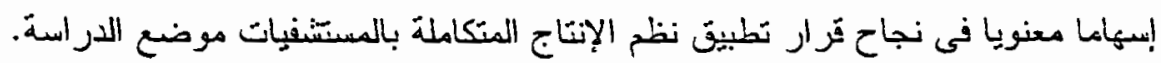
وفى ضوء ذلل فقد قام الباحث بصياغة العلاقة بين هذه العوامل جيعا فـى صسورة 
m

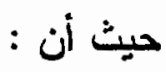

سه : نجاح قرار نطبيت نظم الإتتاج المنكاملة بالمستشفيات موضع الدراسة (المتغير .التابع).

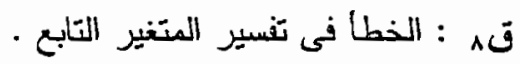
هذا ويوضح الجذول رقم (2) نتانج تحليل هذه العلاقة :

\section{جدول رقت (4)}

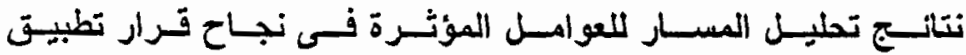
نظم الإنتاج المتكاملة بالمستثفيات موضع الدراسة (س)ر

\begin{tabular}{|c|c|c|c|c|}
\hline الجزئى المعيارى الاحدار & قيمة (ت) & | معامل الاحدار & معامل الارتباط & المتغيرات \\
\hline$\cdot, \cdot v$ & $\cdot, \varepsilon \uparrow$ & $\cdot, \cdot 9$ & $\cdot, \Gamma \varepsilon$ & 1- النوع (سا) \\
\hline,+ 17 & $1, Y 7$ & $\cdot$, YO & $\cdot, 11$ & r- السن (سr) \\
\hline$\cdot, r \wedge$ & $=1,14$ & $1,9 \wedge$ & $\cdots ., 04$ & r- المؤهل العلمى (سr) \\
\hline$\cdot, \cdot r-$ & $\cdot, 1 \mathrm{~V}-$ & $\cdot, \cdot r-$ &., 17 & 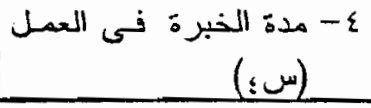 \\
\hline., $0 \varepsilon$ & $* 4.94$ &., 0 & $\because, v r$ & 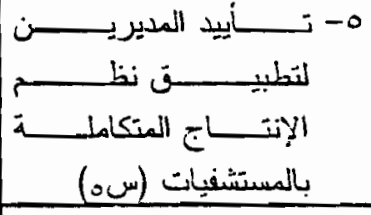 \\
\hline., YO & $1, T 1$ & $\cdot, 10$ & $\cdot, r T$ & 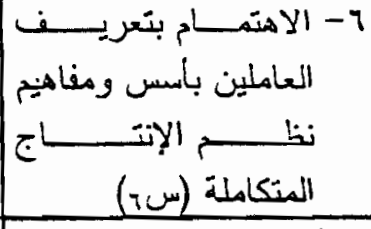 \\
\hline$\therefore r \varepsilon$ & $* r .7 r$ & $\cdot, \cdot r$ & $\because, 59$ & 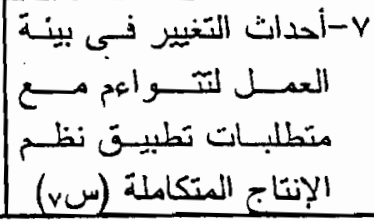 \\
\hline $\begin{array}{l}1 \\
\text { عند } 1 ., 0 \\
\end{array}$ & • • • معنوب & & \multicolumn{2}{|c|}{ 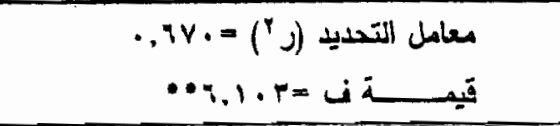 } \\
\hline
\end{tabular}




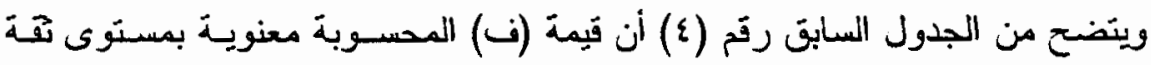

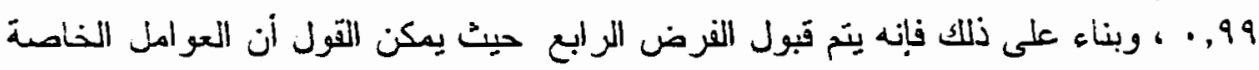

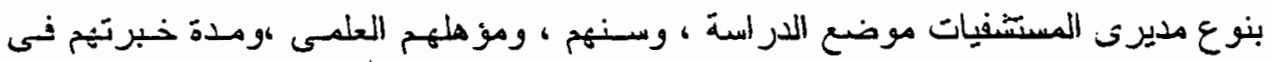

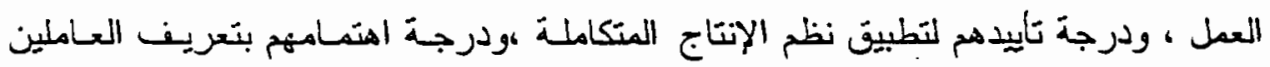

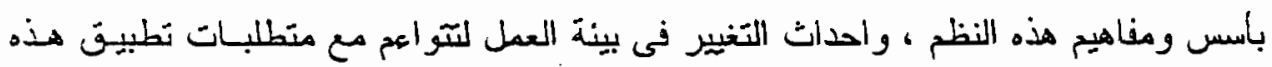

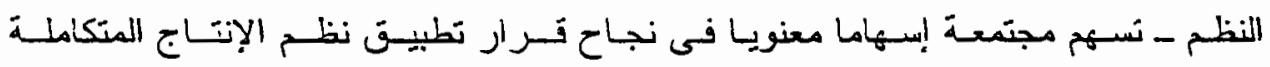
بالمستشفيات موضع الدراسة .

وعلى الرغم من ذللك فان قَيم (ت) ومعاملات المسـار المحسوبة تشير إلى وجـود

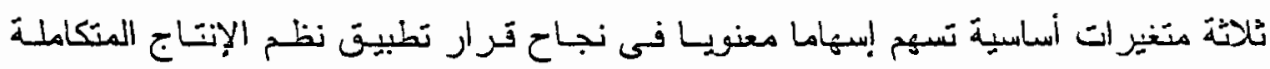
بالمستشفيات موضع اللر اسة.

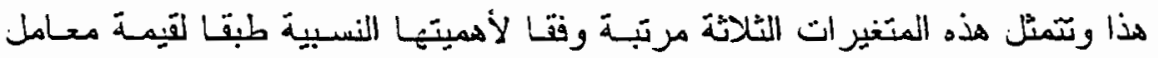

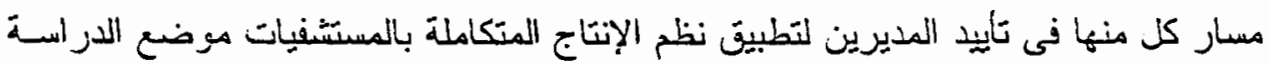

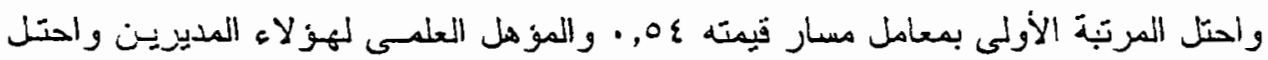

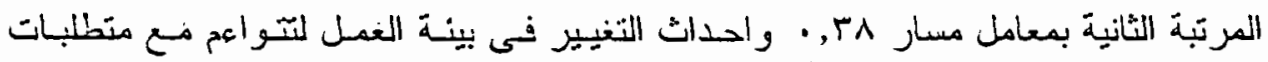

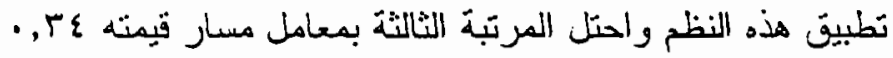
وتوضح نسبة الخطا أن لو\% من التبانين فى درجة نجاع ثرار تطبيق نظم الإنتاج

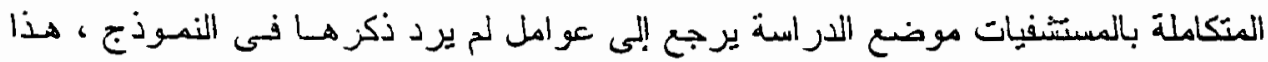

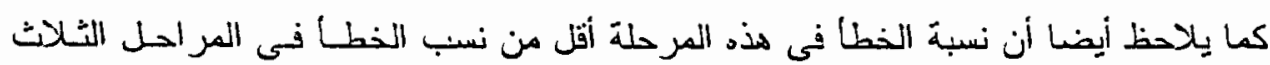
السابقة.

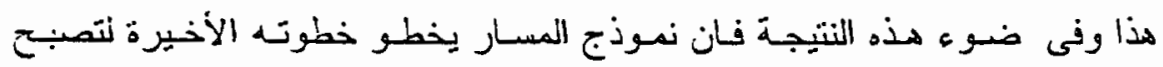

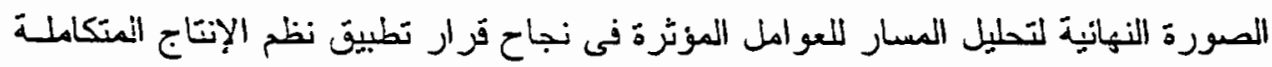

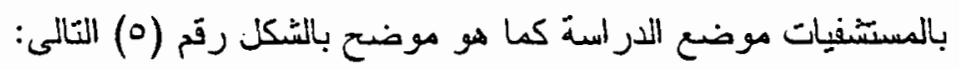




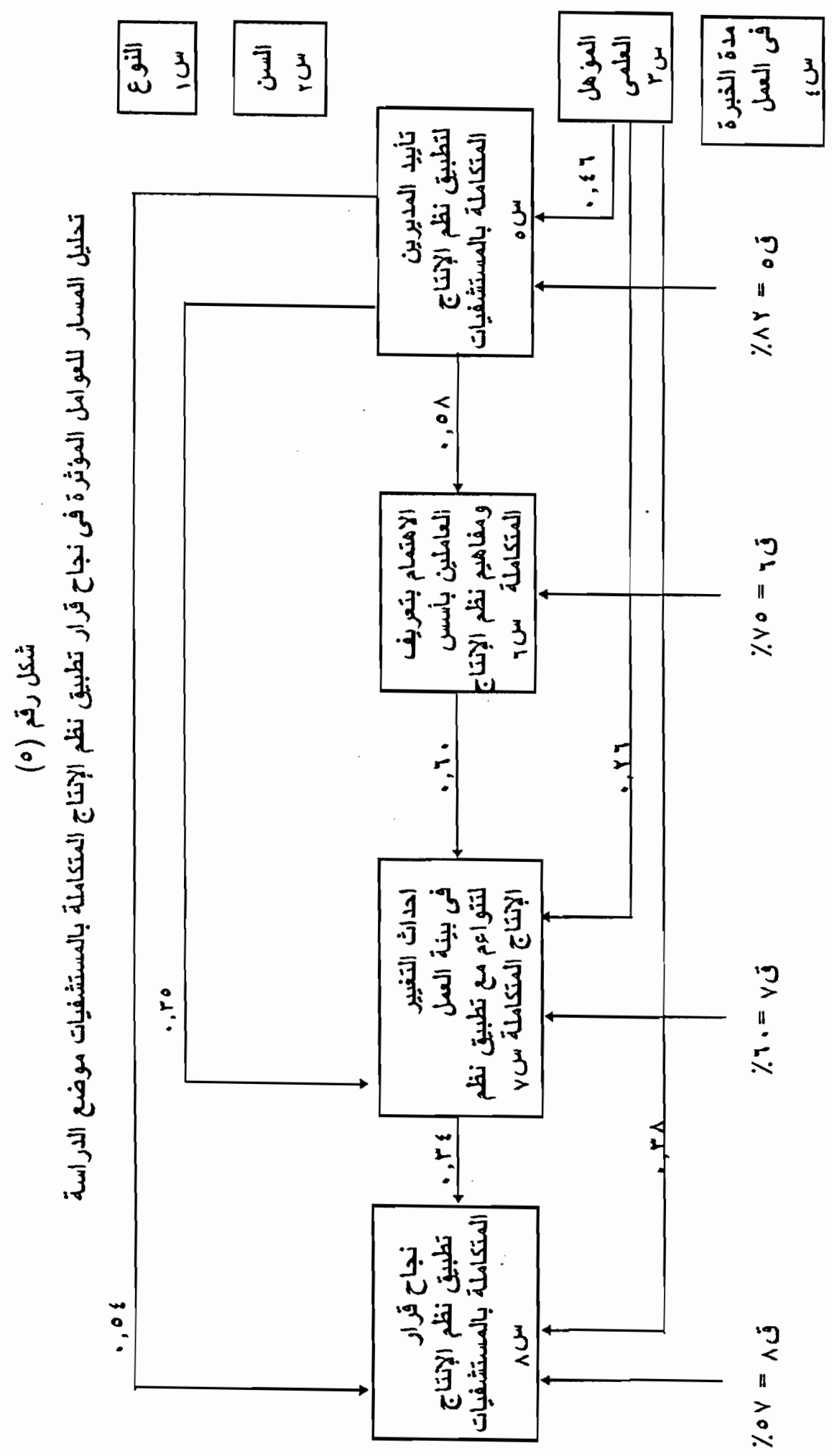




\section{خامسا: النتانج والتوصيات}

\section{نتائج الدراسة:}

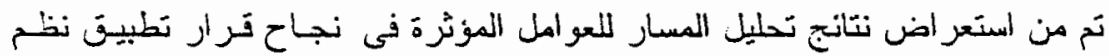
الإنتاج المنكاملة بالمسنشفيات موضع الدراسة التوصل إلى النتانج الأساسية التالية:

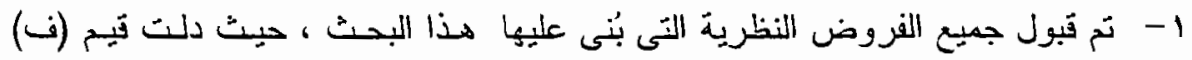

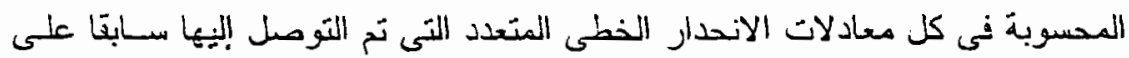

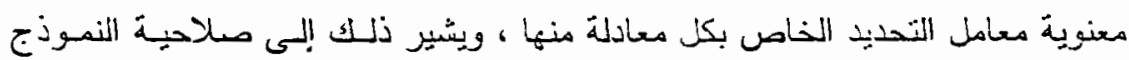

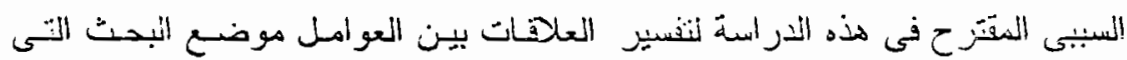
اشتهلت عنيبا هذه الدراسة. Y - تخ هن خلل تحليل قيم معاملات المسار (الاتحدار الجزنى المعيارى ) التوصـل إلى النتائج الثنلاثة التالية:

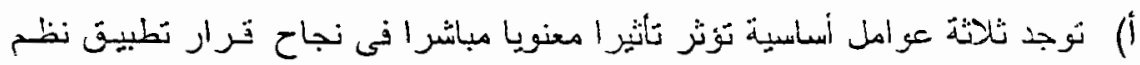

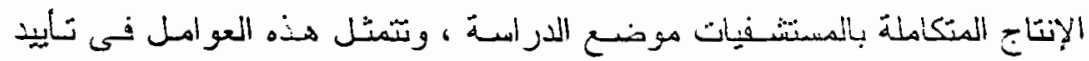
المديرين لتطبيق هذه النظم ، والمؤهل العلمى لهؤلاء المديرين ، و واحداث التغينيز فى بينة العمل لتتو اهم هي منطلبات هذا التطبيق.

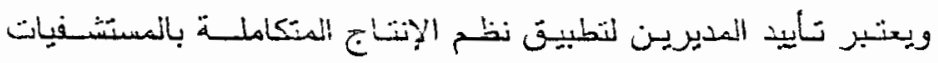

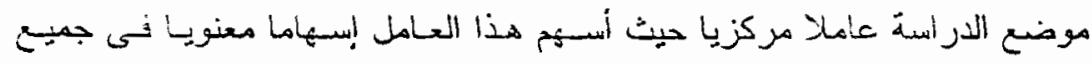

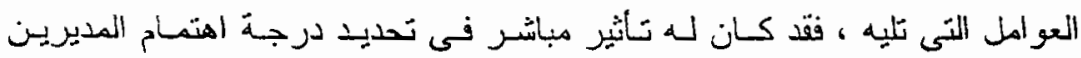

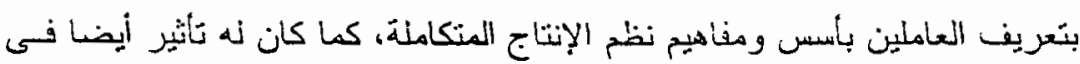

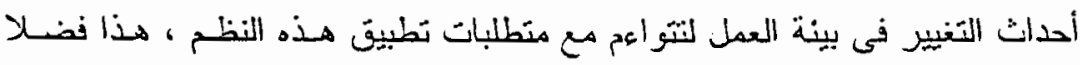
تن تأثيره المباشر فى نجاح فرار تطبيث هذه النظم بالمستشفيات هوضع الدر أسنة. وتزكد هذه الحقيقة صحة ما أشار اليـة كتير من البـاحشين والاداربسين

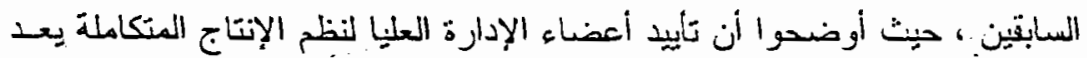

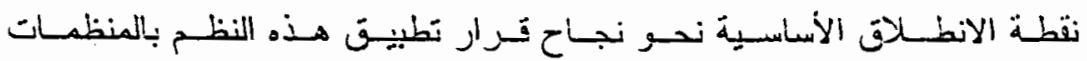
المر اغبة فى ذنلك.

هذا كما يعد المؤهل العلمى للمديرين عن العوامل الأساسية ذات التأثير

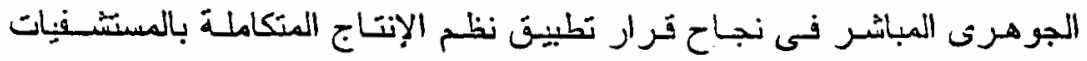


موضع الاراسة ، حيث أوضتح التحليل الإحصانى أنـه كلمـا ارنقى المديرون فيى المستوى العلمى كلما ساعد ذلك على نجاح قرار تطبين هذه النظم.

هذا من ناحية ومن ناحية أخرى ، فان أحداث التخيير في بينة العمل

لتو اهم مع متطلبات تطبيق نظم الإنتاج المتكاملة يعتبر أيضا من العوامل المل الأساسية

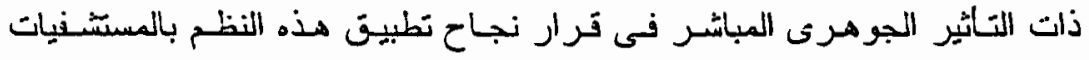

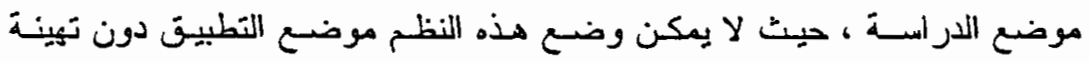

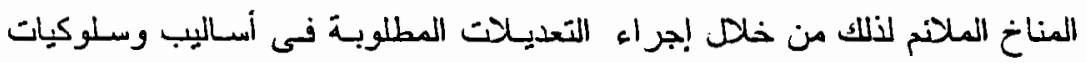

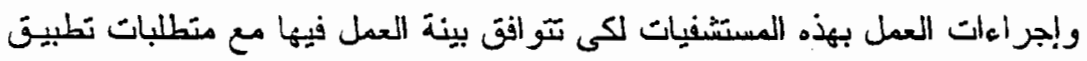
نظم الإنتاج المتكاملة.

ب) يوجد عامل واحد يسهر إبهامأ غير مباشـر فـى نجاح قرار تطبيـن نظم الإنتـاج

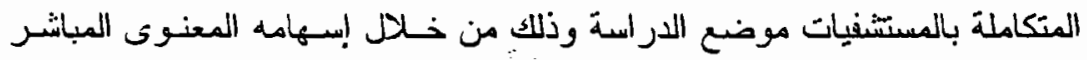

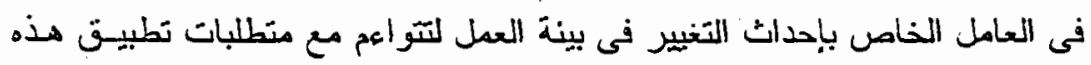

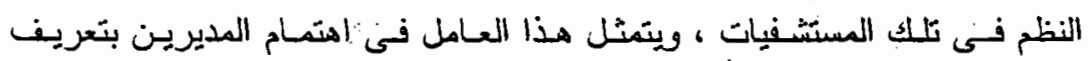
العاملين بالمستشفيات بأسس ومفاهيم نظم الإنتاج المتكاملة.

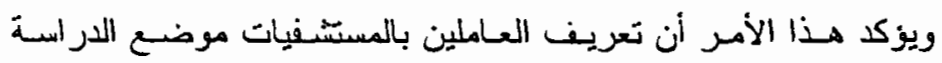

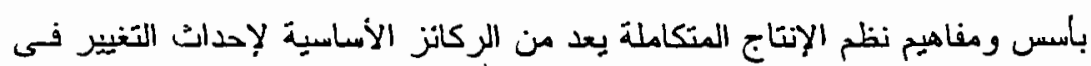
بينة العمل بهذه المستشفيات لتتواءم مع منطلبات تطبيق هذه النظم فيرها.

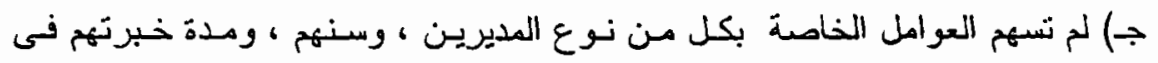

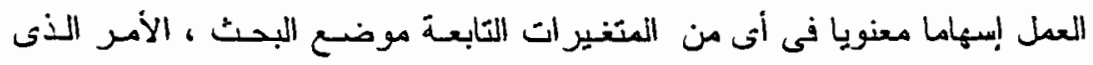
يمكن اعتبار ها هتغيرات خارجية أو هامشية.

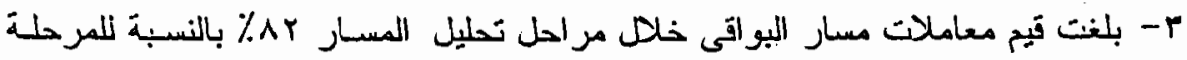

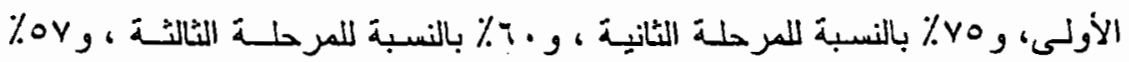

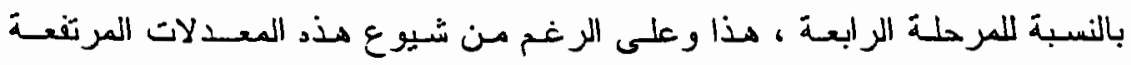

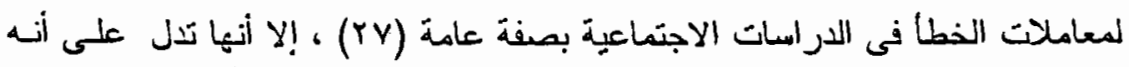

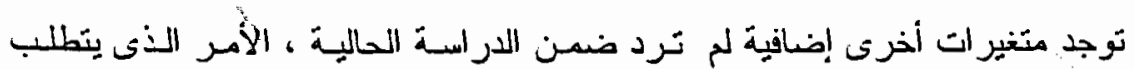

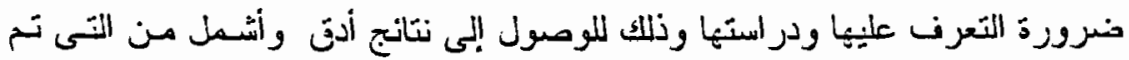
التوصل إليهـا فى هذه الار استة. 
هذا وفى ضوء نموذج تمليل المسار المقتر ح في هذه الدراسة وما ترنتب عليهه هـن

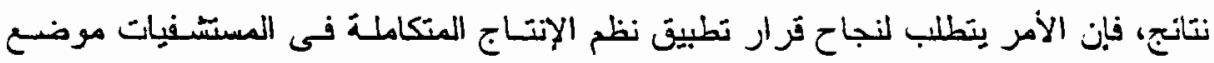

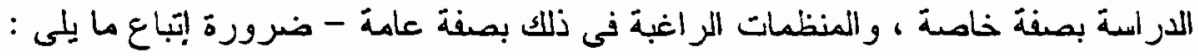
ا- التأكيد على التزام وتعهد أعضـاء الإدارة العليا بتبنى تطبيـت نظم الإتتاج المتكاملة بمنظماتهم.

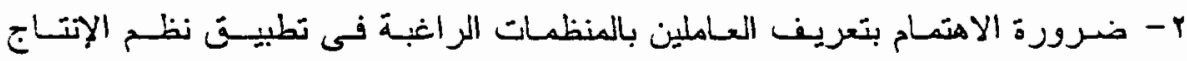

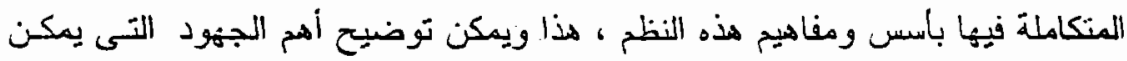

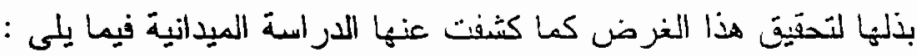

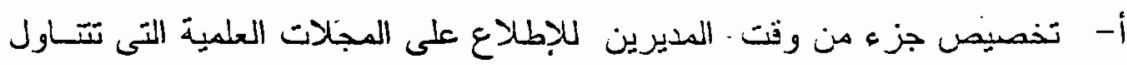
بالشر ح أسس ومفاهيي نظم الإنتاج المنكاهلة. ب- إعداد وتنفيذ برامج تدريبية متخصصة للعاملين لشرح حسمس ومفاهيم نظم الإنتاج المتكاملة.

جـ- تخصيص جزء مـن وفت العمل لمنافتـة المديرين ( أعضـاء الإدارة العليـا ) لمرؤسئه في طبيعة وفلسنة نظم الإنتاج المتكاملة.

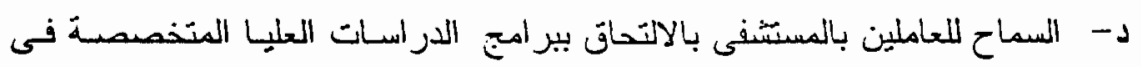

$$
\text { نظم الإنتاج المنكاملة. }
$$

هـ- إنشاء مكتبة بالمستشنى وتزويدها بالمر اجع المتخصصة فى فلسفة نظم الإنتاج المتكاملة.

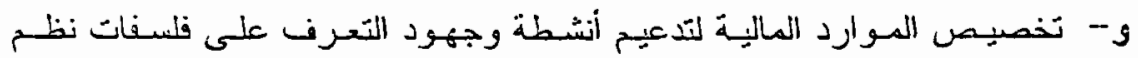

$$
\text { الإنتاج المنكاملة. }
$$

ز- تكريب العاملين على انقيام باكثر من عمل بالمستشنى لتتمية مهار اتمهم. r- الاججاه نحو تغيير بينة العمل بالمنظمات الر اغبة في تطييق نظم الإتتاج المنكاملة فيبا

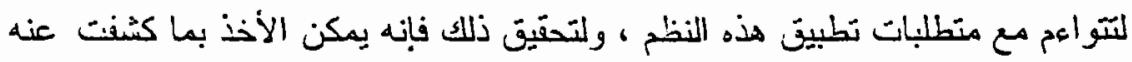

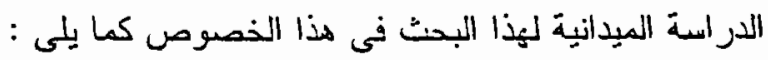
أ- بالنسبة لنظم تكنولوجيِ التصنيع المتقدمة : فلن الأمر يتطلب ضرورة استخدام الكمبيوتر والأجهزة الإكترونية الحديثة فئي: 
ثتظيم عمليات استقبال وإقامة المرضى بالمستشفى.

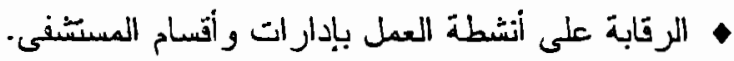
• فحص المرضى.

• • إجر اء عمليات التحاليل والأشعة. • إجراء العمليات الجراء الحية.

ب- بالنسبة لنظام الإتتاج في الموعد بالضبط: فان الأمر بتطلب ضرورة :

تخفيض زمن إعداد وتجهيز الخدمات الصحية. تخفيض وقت انتظار المرضى للخدمة.

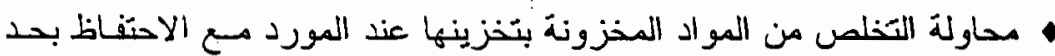

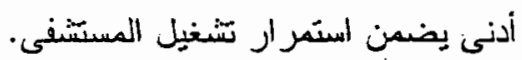

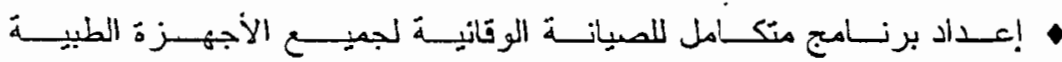

$$
\text { ومبانى المستشفى. }
$$

تصميم المستشفى فى شُكل مر اكز متعددة المهام بحيث بقوم كل مركز بنقديسم

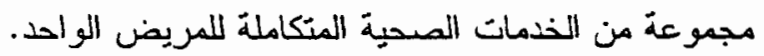

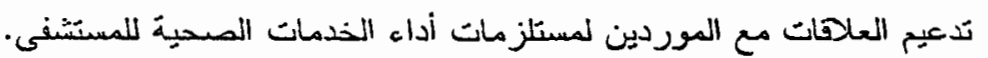

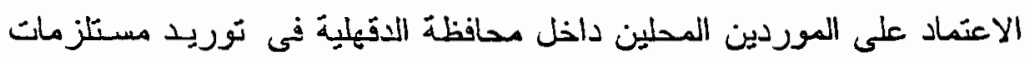

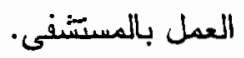

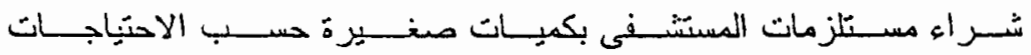
الفعلية للمرضى. هالتعامل مع هورد واحد بدلا من التعامل مع عدة هوردين.

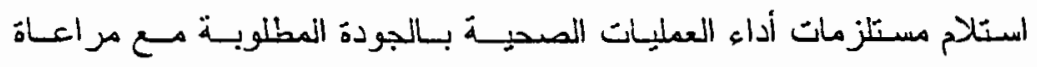
المورد ذلك. عمل نعاقدات طويلة الأجل مع المورد.

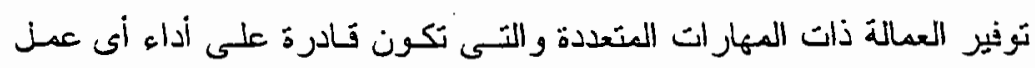
مطلوب منها. • نشغيل المستشفى طبقا لنظام السحب (بمنى تجيميز منطلبات أداء الخذمات بما يتنق مع طلبات المرضى). 
جـ - بالنعبة لإدارة الجودة الشاملة : فإن الأمر ينطلب ضرورة : • أذاء الخدمات الصحية للمرضى دون أخطاء من أول مره.

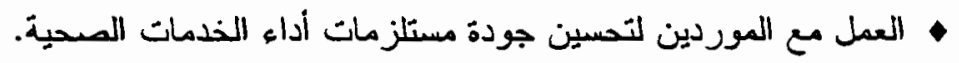
• • التحسين المستمر لأهاكن وأدوات العمل بالمستشنى. هودئ. • قياس وتحديد تكلفة جودة الخدمات الصحية بالمستشفى.

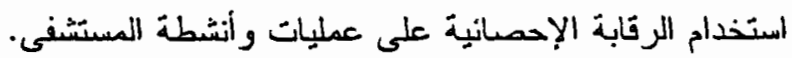

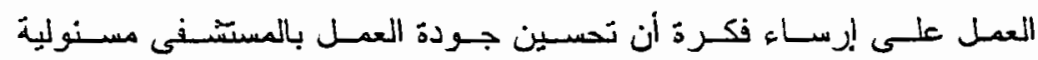
كل الأفراد بها.

• الأخذ بفكرة استمر ار التحسين والتطوير للأعمال بالمستشفى.

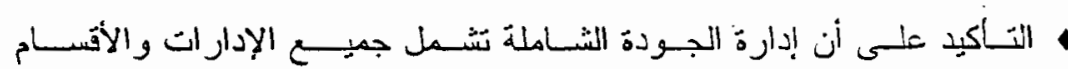
والوحدات بالمستسفى. تصني. نشر منهوم الجودة الشاملة للخدمات الصحية بين جميع العاملين بالمستشنى. 
راجع في ذلك على سبيل المثال:

Snell, Scott A., and Dean, James W., JR., "Integrated

(i)

Manufacturing and Human Resource Management: A Human

Capital Perspective", Academy of Management Journal,

Vol. 35, No. 3, 1992, PP.: 467- 505.

Dean, James W., JR., and Snell, Scott A., "Integrated (ب)

Manufacturing and Job Design: The Moderating Effects of

Organizational Inertia", Academy of Management Joumal,

Vol. 34, No. 4, 1991, PP.: 776- 804.

Schonberger, R. J., World Class Manufacturing: The Lessons of ( $\rightarrow$ )

Simplicity Applied, (New York: Free Press, 1986).

Mortimer, J., (Ed.), Integrated Manufacture, (Berlin: Springer-

Verlag and IFS Publications Ltd., 1985).

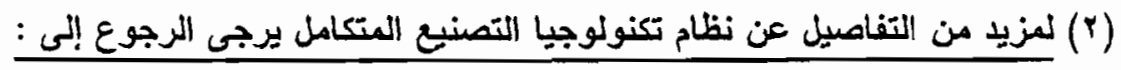

Schmenner, Roger W., Production/ Operations_Management From (i)

The Inside Out, (Fifth Edition, New York: Macmillan Publishing

Company, Inc., 1993), PP.: 470- 475.

Gunn, T.G.,Manufacturing for Competitive Advantage, (New York: (ب)

Free Press, 1987).

Adam, Jr., Everett E., and Ebert, Ronald J., Production and ( $\rightarrow$ )

Operations Management, Concepts, Models, and Behavior, (Fourth

Edition, London: Prentice- Hall International, Inc., 1989),

PP.: $125-126$.

\section{(r) لمزيد من التفاصيل عن نظام الإتتاج في الموعد بالضبط يرجى الرجوع إلى:}

Cheng, T.C.E., and Podolsky, S., Just - in - Time Manufacturing

An Introduction, (London: Champan\& Hall, 1993).

Dilworth, James B., Operations Management - Design, Planning

and Control for Manufacturing and Services, (New York: McGraw Hill, Inc., 1992), PP.: 489 - 505.

Goyal , S ., and Deshmukh, S., "A Critique of the Literature on Just ( $\rightarrow$ )

in - Time Manufacturing", International Journal of Operations and

Production Management, Vol. 12, No. 1, 1992, PP.: 18 -28. 
Kramarker ,U. , "Getting Control of Just - in- Time", Harvard

Business Review, Vol. 67, No. 5, 1989, PP.: 122 - 131.

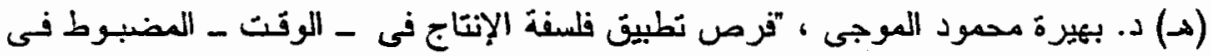

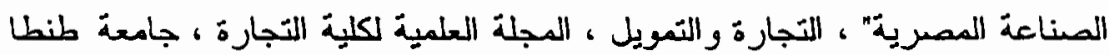

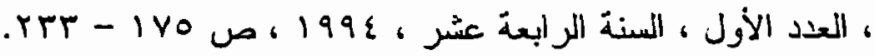

$$
\begin{aligned}
& \text { (أ) لمزيد من التفاصبل عن إدارة الجودة الشاملة يرجى الرجوع إلى: }
\end{aligned}
$$

Pike, J., and Bames, R., TQM in Action: A Practical Approach to (i)

Continuous Performance Improvement, (London: Chapman \& Hall, 1994).

Wies, Howard J., and Gershon, Mark E., Production and Operations (ب) Management,(Second Edition, London: Allyn and Bacon, 1993), PP.: 759 - 785.

Hakes, C., (Ed.), Total Quality Management: The key to Business (-ج) Improvement, (London: Chapman \& Hall, 1991).

Oakland, J.S., Total Quality Management, (London: Heinemann, 1989).

(هـ) د. كامل السيد غراب ، "الربـ بين إبستراتيجية التطويـر التكنولوجى و أسـاليب إدارة

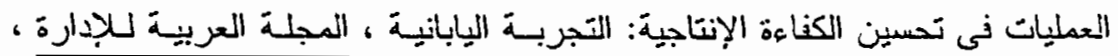

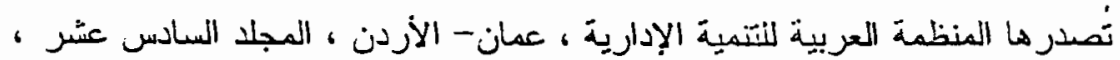

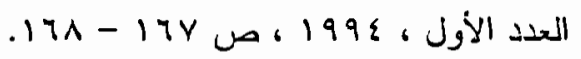

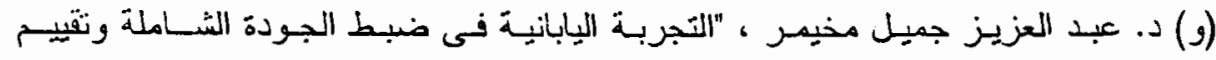

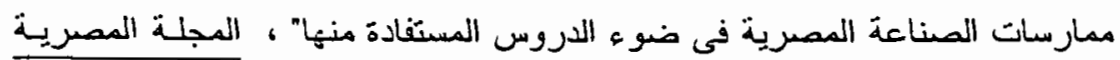

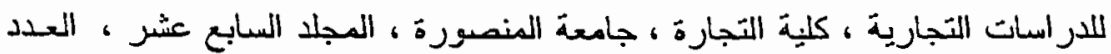

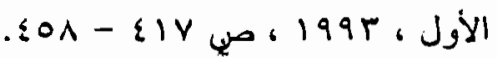

$$
\begin{aligned}
& \text { (0) راجع فى ذلك على سبيل المنال: }
\end{aligned}
$$

Billesbach, Thomas J., "A Study of the Implementation of Just in - Time in the United States", Production and Inventory Management Joumal, Vol. 32, No. 3, 1991, P.P.: 1-4.

Schonberger, R. J., "The Transfer of Japanese Manufacturing Management Approaches to U.S. Industry", The Academy of Management Review, Vol. 7, No. 3, July 1982, PP.: 479 - 487. 
(ج) د. نتحى على محرم ، د. عبد القادر محمد عبد القادر ، إدارة الإنتاج والعمليLات

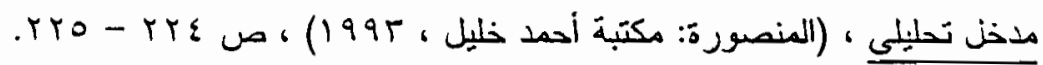

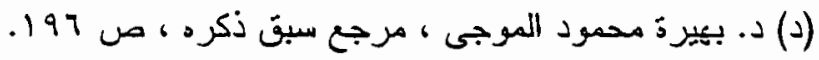

(7)(أ) د. حسين عطا غنيم ، مقدمة في إدارة الإنتاج والعمليات ، (الطبعة النالثة ، القاهرة: دار

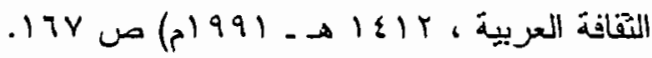

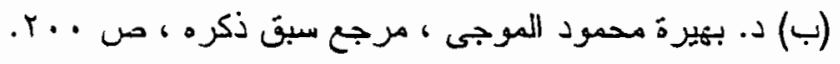

Hayes, Robert H., and Ramchandran, Jaikumer, "Requirements For (i)(v) Successful Implementation of New Manufacturing Technologies", Joumal of Engineering and Teclnology Management Vol. 7, No. 3, March 1991, PP.: 169 - 175.

Ansari, Ahsanuddin, "Survey Identifies Critical Factors in Successful(ب) Implementation of Just - in - Time Purchasing Techniques, Industrial Engineering, Vol. 18, No. 10, 1986, P.P.: 44 - 50.

Safayeni, F., and Others, "Difficulties of Just - in - Time

Implementation A Classification Scheme", International Joumal of

Operations and Production Management, Vol. 11, No. 7, 1991, PP.: 27 - 36.

$$
\begin{aligned}
& \text { (ب) د. بثيرة محمود الموجى ، مرجع سبق ذكره ، ص } 197 \text { - 19 1. }
\end{aligned}
$$

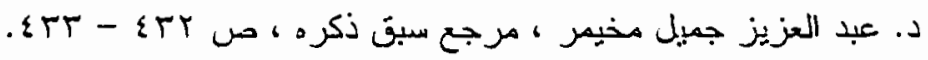

$$
\begin{aligned}
& \text { (1. ) راجع في ذلك على سبيل المثال: }
\end{aligned}
$$

Harber, D., and Others , "Just - in -Time: The Issue of (i) Implementation", International Joumal of Operations and Production Management, Vol. 10 , No. 1, 1989, PP.: 21-30.

$$
\begin{aligned}
& \text { (ب) د. بيرة محمود الموجى ، مرجع سبق ذكره، ص } 197 . \\
& \text { : (II) راجع في زللك على سبيل المثال: }
\end{aligned}
$$

Schonberger, R.J., "Just - in - Time Production System (i) Replacing Complexity With Simplicity in Manufacturing Management, Industrial Engineering, October 1984, PP.: 52 - 63.

$$
\text { (ب) د. بهيرة محمود الموجى ، مرجع سبق ذكره ، ص - } 197 \text { - 197 : } 192
$$

Safayeni, F., and Others, Op. Cit., PP.: 27 - 36. 


$$
\begin{aligned}
& \text { (IT) د. بهيرة محمود الموجى ، مرجع سبت ذكره ، ص ع . ؟. }
\end{aligned}
$$

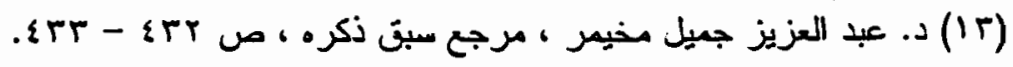

$$
\begin{aligned}
& \text { (1 إجع في ذللك على سبيل المثال: }
\end{aligned}
$$

Snell, Scott A., and Dean, James W., JR., Op. Cit., PP.: 486 - 493.

Dean, James W., JR., and Snell, Scott A., Op. Cit., PP.: 789-799. (ب)

$$
\text { (10) راجع في ذلك على سبيل المثال: }
$$

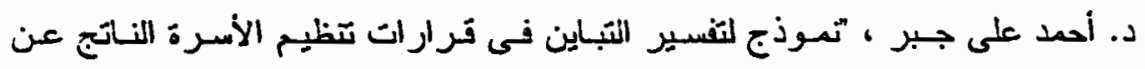

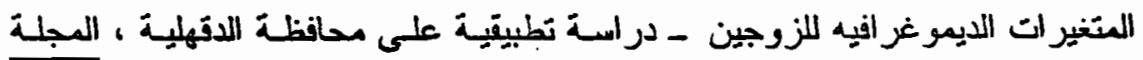

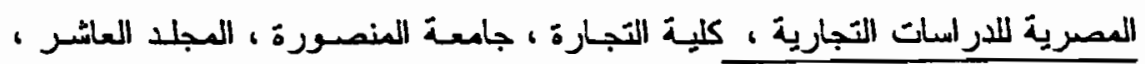

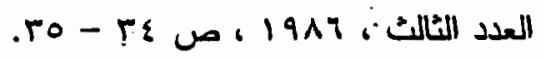

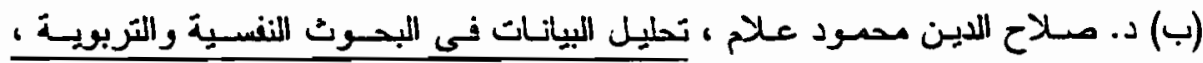

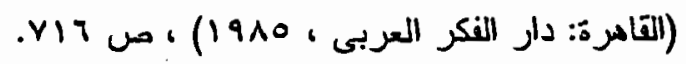

$$
\begin{aligned}
& \text { (17)(17) د. بهيرة محمود الموجى ، مرجع سبق ذ ذكره ، ص }
\end{aligned}
$$

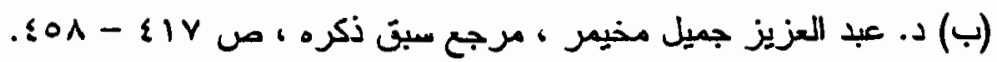

: IV) راجع في ذلله على سبيل المنال: (IV)

Krajewski, Lee J., and Ritzman, Larry P., Operations Management (i) Strategy and Analysis, (Third Edition, New York: Addison - Wesley Publishing Company, 1993), PP.: 712 - 714.

Evans, James R., Applied Production and Operations Management, ب) (Fourth Edition, New York: West Publishing Company, 1993), PP.: $284-287$.

James, E. Swiss, “Adapting Total Quality Management (TQM) to Government", Public Administration Review, Vol. 25, No. 4, July - August 1992, PP.: 356 - 369.

Inman, R., and Mehra, S., "JIT Applications for Service Environments", Production and Inventory Management Joumal, Vol. 32, No. 3, 1991, PP.: 16 - 21 . 


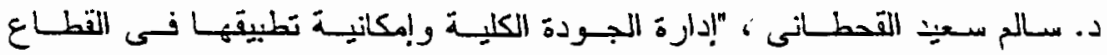

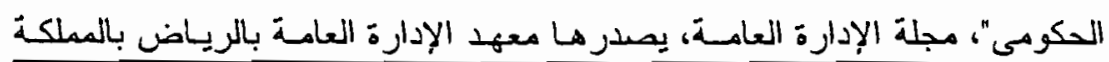

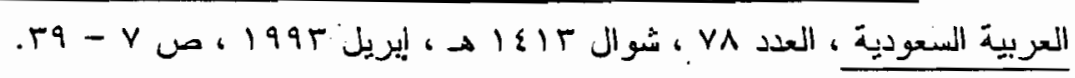

Wonnacott, Thomas H., and Wonnacott, Ronald J., Introductory

Statistics, (Fifth Edition, New York: John Wiley \& Sons, 1990), PP.: $423-428$.

Watson, Collin J., and Others, Statistics for Management and Economics, (Boston: Allyn and Bacon, A Division of Simon \&

Shuster, Inc., 1990), PP.: 645 - 700.

Kleinbaum, David G., and Others, Applied Regression Analysis and (ب)

Other Multivariable Methods, (Boston: PWS - Kent Publishing

Company, 1988), PP.: $36-143$.

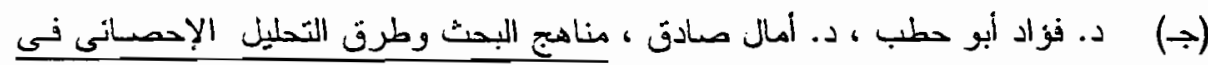

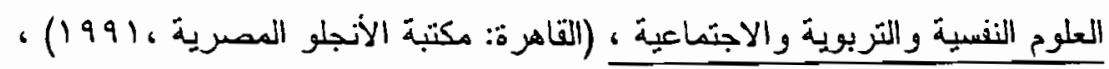

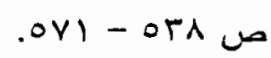

Walpole, Ronald E., Introduction To Statistics, New York:

Macmillan Publishing Co., Inc., 1990), P.P.: 374 - 378.

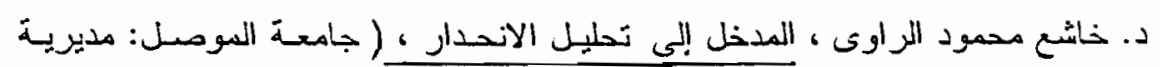

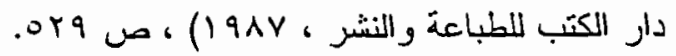

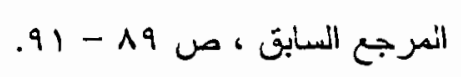

د. أنور رياض عبد الرحيم ، تأثير الذكاء والبينة الأسرية والواجب المدرسى ومشـاهدة بر امبج التليفزيون نى التحصيل الدراسى: دراسة باستخدام تحليل المسار" ، مجلة البحث

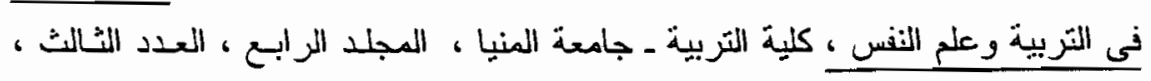

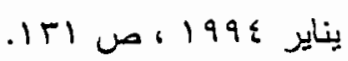

$$
\begin{aligned}
& \text { لمزيذ من التفاصيل عن تلك الشروط يرجى الرجوع إلى: } \\
& \text { د. أحمد على جبر ، مرجع سبق ذكره ، ص كاء. }
\end{aligned}
$$

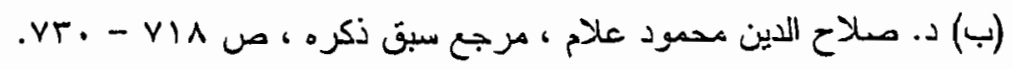


$-119-$

(ro)

والمزكزية والجامعية والتخصصية بمر اكز محافظة الدقهلية ، ديسمبر عام ع 199.

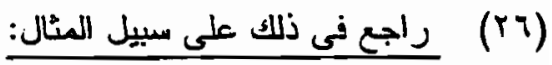

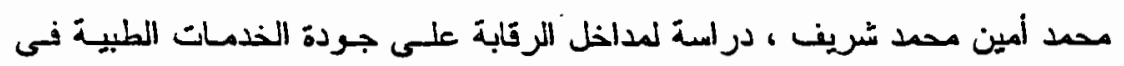

(i)

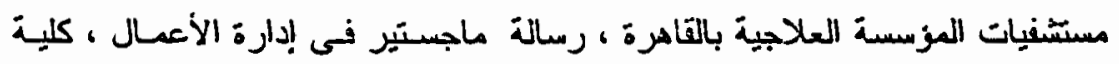

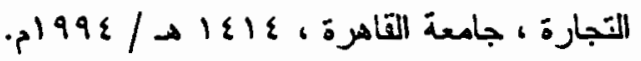

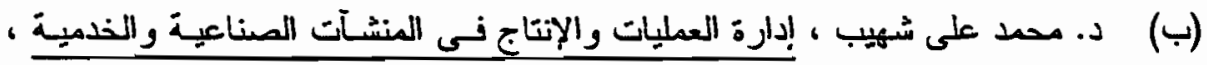

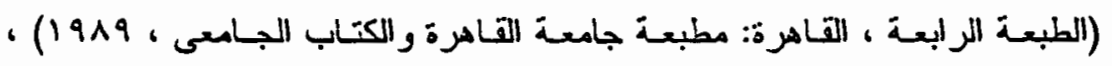

D

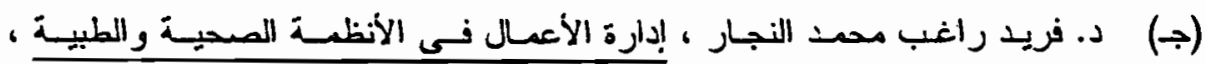

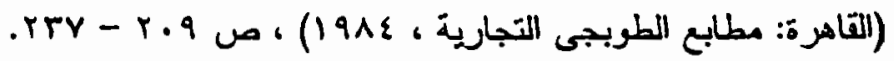




\section{قائمة المراجع}

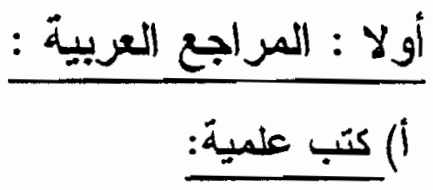

ا- د. حسين عطا غنيم ، مقدمة في إدارة الإنتاج والعمليـات ، (الطبعة الثالثة القاهرة: دار

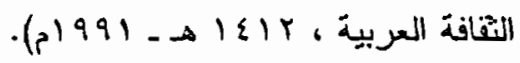

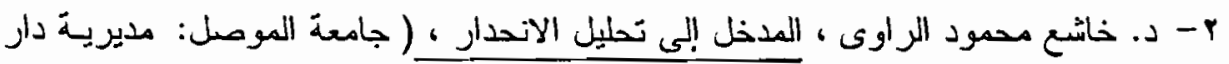

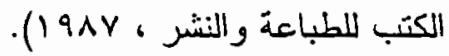
ب- د. دملاح الدين محمود علام ، تحليل البيانات في البحوث النفسية و الثربويسة ، (القاهرة:

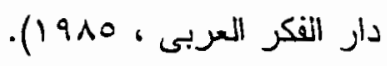

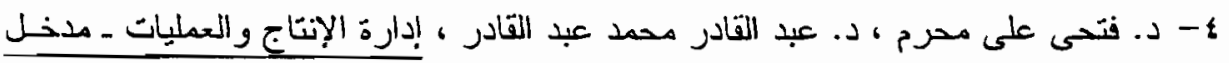

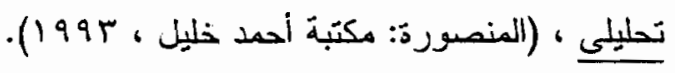

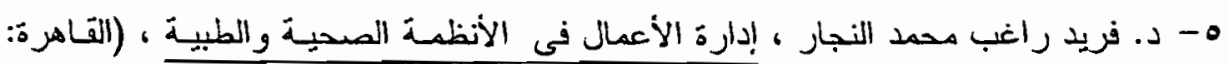

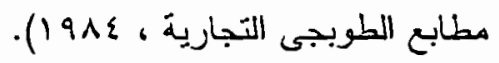

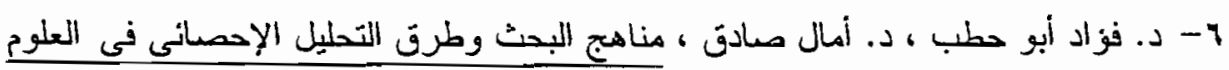

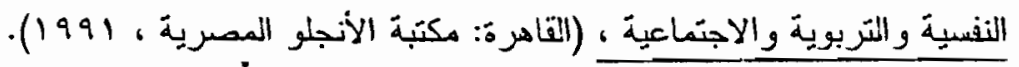

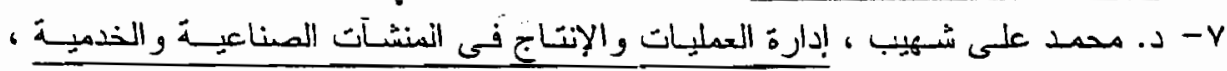

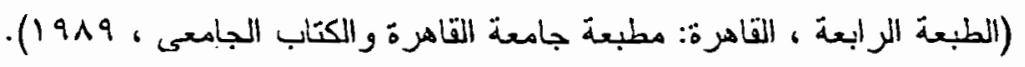

$$
\text { ب) بحوث ودزراسات علمية : باتئ }
$$

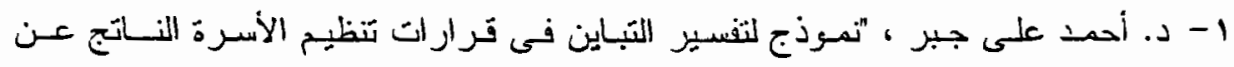

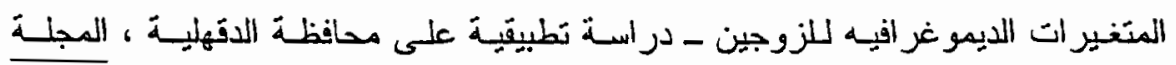

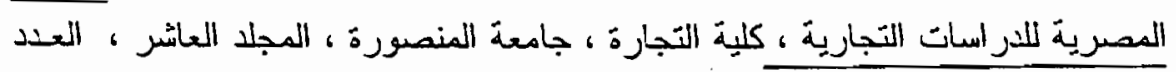
الثانت ، 1917.

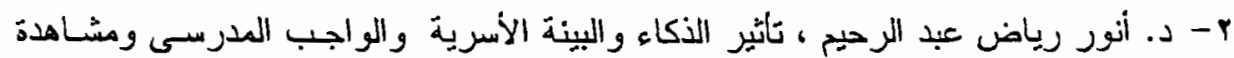

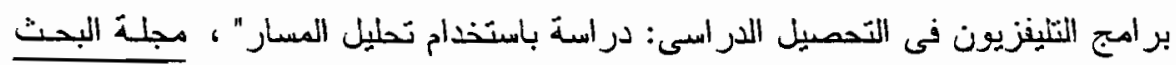

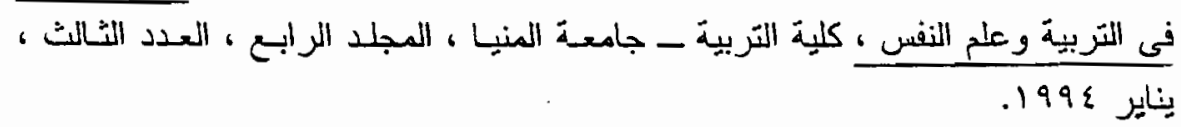

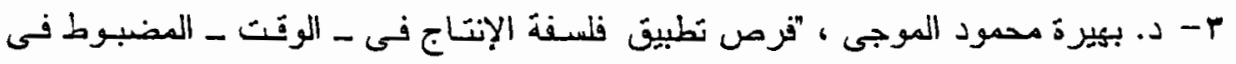

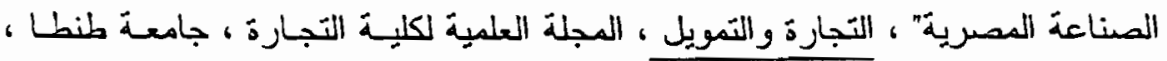




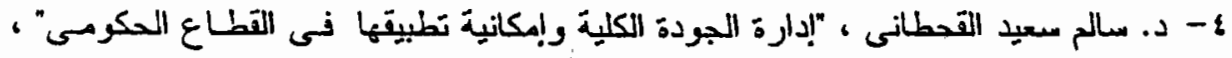

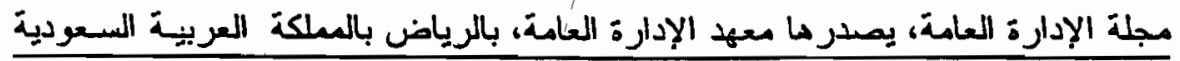

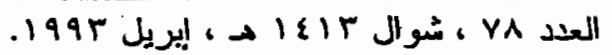

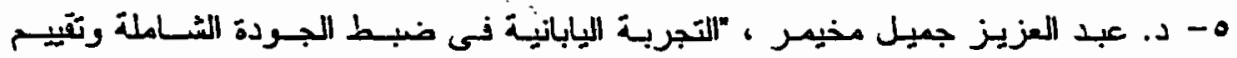

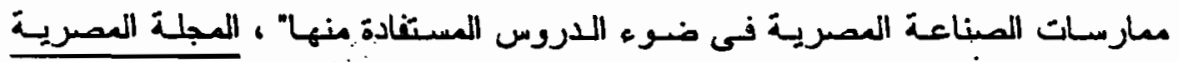

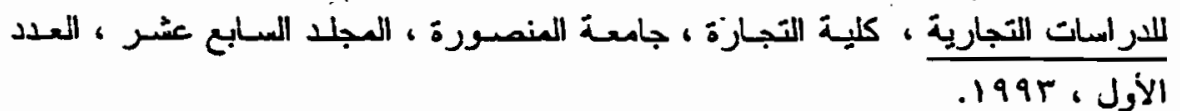

צ- د. كامل السبيد غراب ، "الربط بيـن إسـتراتيجية التطويـر التكنولرجى وأسبـاليب إدارة

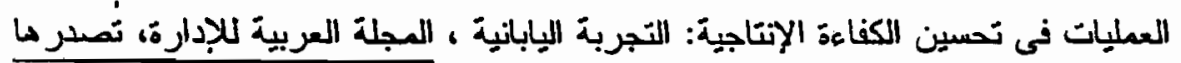

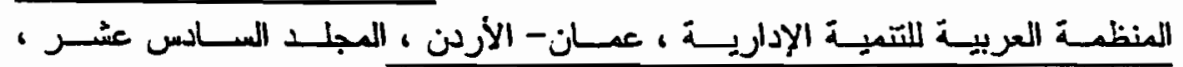

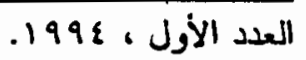

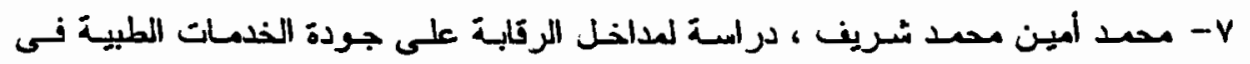

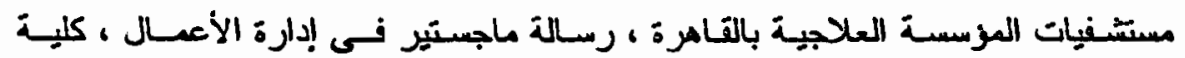

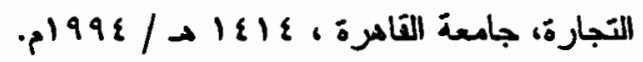
ج) سجلات ونشرات :

- مديرية الشنون المحية بالاقهلية ، إدارة الإحصناء ، بيـان أعداد المستشفيات العامسة

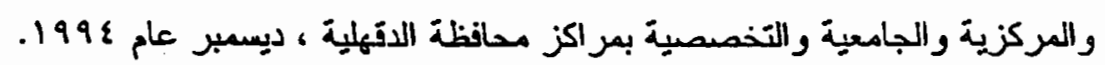

ثُأنيا : المراجع الأجنبية :

\section{A) BOOKS:}

1) Adam, Jr., Everett E., and Ebert, Ronald J., Production and Operations Management, Concepts, Models, and Behavior, (Fourth Edition, London: Prentice- Hall International, Inc., 1989).

2) Cheng, T.C.E., and Podolsky, S., Just - in - Time Manufacturing An Introduction, (London: Champan\& Hall, 1993).

3) Dilworth, James B., Operatious Management - Design, Planning and Control for Manufacturing and Services, (New York: Mcgraw Hill, Inc., 1992).

4) Evans, James R., Applied Production and Operations Management. Fourth Edition, New York: West Publishing Company, 1993).

5) Gunn, T.G., Manufacturing for Competitive Adyantage, (New York: Free Press, 1987). 
6) Hakes, C., (Ed.), Total Quality Management: The key to Business Improvement, (London: Chapman \& Hall, 1991).

7) Kleinbaum, David G., and Others, Applied Regression Analysis and Other Multivariable Methods, (Boston: PWS - Kent Publishing Company, 1988).

8) Krajewski, Lee J., and Ritzman, Larry P.,Operations Management Strategy and Analysis, (Third Edition, New York: Addison - Wesley Publishing Company, 1993.

9) Mortimer, J., (Ed.), Integrated Manufacture, (Berlin: Springer- Verlag and IFS Publications Ltd., 1985).

10) Oakland, J.S., Total Quality Management, (London: Heinemann, 1989).

11) Pike, J., and Barnes, R., TQM in Action: A Practical Approach to Continuous Perfornance Improvement, (London: Chapman \& Hall, 1994).

12) Schmenner, Roger W., Production / Operations Management From The Inside Out, (Fifth Edition, New York: Macmillan Publishing company, Inc., 1993), PP.: 470- 475.

13) Schonberger, R. J., World Class Manufacturing: The Lessons of Simplicity Applied, (New York: Free Press, 1986).

14) Walpole, Ronald E., Introduction To Statistics, (New York: Macmillan Publishing Co., Inc., 1990).

15) Watson, Collin J., and others, Statistics for Management and Economics, (Boston: Allyn and Bacon, A Division of Simon \& Shuster, Inc., 1990.

16) Wies, Howard J., and Gershon, Mark E., Production and Operations Management,(Second Edition, London: Allyn and Bacon, 1993).

17) Wonnacott, Thomas H., and Wonnacott, Ronald J., Introductory Statistics,(Fifth Edition, New York: John Wiley\& Sons, 1990).

\section{B) PERIODICALS:}

1- Ansari, Ahsanuddin, "Survey Identifies Critical factors in Successful Implementation of Just - in - Time Purchasing Techniques, Industrial Engineering, Vol. 18, No. 10, 1986.

2- Billesbach, Thomas J., "A Study of the Implementation of Just - in Time in the United States", Production and lnventory Management Journal, Vol. 32, No. 3, 1991. 
3- Dean, James W., JR., and Snell, Scott A., "Integrated Manufacturing and Job Design: The Moderating Effects of Organizational Inertia", Academy of Management Journal, Vol. 34, No. 4, 1991.

4- Goyal , S ., and Deshmukh, S., "A Critique of the literature on Just in - Time Manufacturing", International Journal of Operations and production Management, Vol. 12, No. 1, 1992.

5- Harber, D., and others, "Just - in -Time: The Issue of Implementation", Intemational Joumal of Operations and Production Management, Vol. 10 , No. 1, 1989.

6- Hayes, Robert H., and Ramchandran, Jaikumer, "Requirements for Successful Implementation of New Manufacturing Technologies", Journal of Engineering and Technology Management, Vol. 7, No. 3,4, March 1991.

7- Inman, R., and Mehra, S., "JIT Applications for Service Environments", Production and Inventory Management Journal, Vol. 32, No. 3, 1991 .

8- James, E. Swiss, "Adapting Total Quality Management (TQM) to Government", Public Administration Review, Vol. 25, No. 4, July August 1992.

9- Kramarker ,U. , "Getting Control of Just - in- Time", Harvard Business Review, Vol. 67, No. 5, 1989.

10- Safayeni, F., and others, "Difficulties of Just - in - Time Implementation A Classification Scheme", International Joumal of Operations and Production Management, Vol. 11, No. 7, 1991.

11- Schonberger, R.J., "Just - in - Time Production System Replacing Complexity With Simplicity in Manufacturing Management, Industrial Engineering,October 1984.

12- Schonberger, R. J., "The Transfer of Japanese Manufacturing Management Approaches to U.S. Industry", The Academy of Management Review Vol., 7, No. 3, July 1982.

13- Snell, Scott A., and Dean, James W., JR., "Integrated Manufacturing and Human Resource Management: A Human Capital Perspective", Academy of Management Journal, Vol. 35, No. 3, 1992. 